\title{
Development and Optimisation of an Amperometric Immunosensor for the Detection of Banned Antibiotic Residues in Honey ${ }^{\dagger}$
}

\author{
Valérie Gaudin *, Caroline Bodin, Céline Hédou, Christophe Soumet and Eric Verdon \\ Anses, Laboratory of Fougeres, European Union Reference Laboratory (EU-RL) for Antimicrobial and Dye \\ Residue Control in Food-Producing Animals, La Haute Marche-Javené, 35302 Fougères, France; \\ * Correspondence: valerie.gaudin@anses.fr \\ + Presented at the 1st International Electronic Conference on Biosensors, 2-17 November 2020; Available \\ online: https://iecb2020.sciforum.net/.
}

Received: date; Accepted: date; Published: date

\begin{abstract}
Veterinary drugs could contaminate animal derived food products for human consumption. Some antibiotic residues (e.g., Chloramphenicol (CAP), nitrofuran metabolites) are banned in foodstuffs of animal origin (e.g., milk, honey, etc.) in European Union because of toxicological risks for the consumer. Screening methods applied for food safety monitoring should be sensitive, specific, cheap, quick, and portable for the field-testing (e.g., self-control). Electrochemical biosensors make it possible to develop a promising and economically interesting approach. An innovative and cheap electrochemical method based on disposable Screen Printed Carbon Electrodes (SPCE), coupled to magnetic beads (MB), allowing the simultaneous detection of 3 families of antibiotics in milk, was published by a Spanish academic team [1]. When the biosensor method was applied to detect CAP residues in honey, two major issues were faced: firstly, the very low levels of residues to reach (i.e., Regulatory limits below $1 \mu \mathrm{g} / \mathrm{kg}$ ), secondly the complexity of honey matrix. There is not a single honey matrix. Honey composition and colour vary considerably depending on the botanical origin. Moreover some honey ingredients can interfere with the electrochemical detection, especially substances with antioxidant activities (e.g., polyphenols). Therefore in parallel with the optimization of the electrochemical method, the reduction of matrix effects was a big challenge.
\end{abstract}

Keywords: amperometric; immunosensor; screening; antimicrobial residues; honey

\section{Introduction}

Antimicrobial substances can be used to treat animals for preventive or curative purposes. The treatments could lead to the presence of residues because of the distribution of the active substance in the animal body, its metabolisation and excretion. Therefore antimicrobial residues could be found in animal derived food products (e.g., Milk, meat, eggs, honey, etc.). For authorized antimicrobials, Maximum Residue Limits (MRL) have been established for the consumer protection, based on toxicological data and food consumption [1]. Nevertheless, some antimicrobials with proven toxicity have been banned for use in livestock animals. For banned substances, Minimum Required Performance Limit (MRPL) have been defined [2]. The MRPL corresponds to the minimum content of an analyte in a sample, which at least has to be detected and confirmed. In order to monitor the presence of these residues in different foodstuffs, surveillance and control plans (SCPs) are put in place in each Member State, according to Directive 96/23/EC [3], now replaced by Regulation (EU) No 2017/625 [4]. Two types of methods are implemented in monitoring plans firstly screening methods, which generally gives a qualitative result (positive (suspect) or negative (compliant)). If the Proceedings 2020, 4, x; doi: FOR PEER REVIEW www.mdpi.com/journal/proceedings 
result is positive, a confirmation step is required, to identify and quantify the antimicrobial residues. Confirmatory methods are physico-chemical methods necessarily based on liquid chromatography coupled mass spectrometry in tandem (LC-MS/MS). MRPL have been set to harmonise the analytical performance of these methods.

The screening step is crucial because it is the first step of the control. Screening methods should be cheap, quick, sensitive ( $<5 \%$ of false negative results), specific for banned antimicrobials, and with high throughput of samples. Chloramphenicol (CAP) is an efficient, cheap and wide spectrum antimicrobial. It is banned since 1993 because of risks of aplastic anemia and bone marrow suppression [5,6]. Bees, like all animals, are susceptible to bacteria, viruses, and parasites (e.g., American foulbrood). Very few treatments are authorized in apiculture. Even authorized antimicrobials for other food-producing animals are not authorized in bee products. Chloramphenicol is also banned in honey and other bee products. However illegal use of CAP could lead to the presence of residues in honey. It is of utmost importance to look for antimicrobial residues in honey. The monitoring of antimicrobials in honey is performed by official control laboratories and by industries for autocontrol purposes. The MRPL of CAP was set at $0.3 \mu \mathrm{g} / \mathrm{kg}$ for all animal derived food products.

Immunological methods (i.e., ELISA kits, radioimmunoassays (RIA)) and LC-MS/MS methods are commonly used methods. ELISA tests are available for the screening of CAP in food products at or below MRPL [7], and especially in honey [8-10]. Historically, immunological methods were the only ones used for the screening of CAP. For twenty years, the LC-MS/MS methods have been used more and more in official control. They gradually replace the biological ones because they allow identifying and quantifying a large number of antimicrobials with a single method (broad spectrum), with very good specificity and lower detection levels than those of biological methods. Each ELISA test is able to detect only one single compound $[8,11]$. On the opposite, multi-residue LC-MS/MS methods have been develop for the screening (identification) of several banned substances simultaneously [12-14]. However LC-MS/MS methods need high cost equipment and specifically trained people. These systems are not fitted for field controls. The multiplexing potential of biosensors could be an alternative to LC-MS/MS methods for simultaneous detection of several antimicrobial residues. A commercial system, named Evidence Investigator ${ }^{\mathrm{TM}}$ (Randox, United Kingdom) is based on Biochip array technology (BAT) and on chemiluminescence detection. The detection of CAP in honey could be performed using a kit named AM III ${ }^{\circledR}$ specific for the detection of CAP or AM V for the simultaneous detection of CAP and nitroimidazoles. However it is a quite expensive method regarding the investment in the system and the cost of the kits. On the contrary, our project is aimed to develop a cheap and sensitive biosensor for the detection of CAP. The perspective will be to develop an innovative multiplex amperometric biosensor for the simultaneous detection of CAP and nitrofuran metabolites in honey. Attempts have been made to develop optical biosensors (e.g., Surface Plasmon Resonance (SPR) for the screening of CAP in different food matrices $[15,16]))$. However the high cost of investment has considerably slowed down the field applications of this system. Electrochemical biosensors represent a promising alternative to optical biosensors especially for food safety applications because they are cost-effective, quick and portable systems [17-19].

Most of the biosensors developed for the detection of CAP were optical (colorimetric, fluorimetric) and electrochemical biosensors [20]. Colorimetric sensors are interesting because of their naked-eye potential, when fluorimetric sensors require an instrumental reading. Optical biosensors allow developing sensitive, specific, simple and quick biosensors for CAP detection. The detection capabilities of electrochemical sensors were proved lower than those of optical sensors. Especially voltammetric and electrochemiluminescent sensors were the most sensitive ones. Therefore we decided to focus this work on electrochemical biosensors as a cheap, sensitive and selective alternative to ELISA tests and LC-MS/MS methods. Electrochemical biosensors for the detection of antimicrobial residues were firstly developed based on antibodies as recognition elements (i.e., Immunosensors). More recently, aptasensors are more and more present in the literature [20]. However very few aptamers against antimicrobials are commercially available. The 
detection methods for electrochemical biosensors are diverse (i.e., Amperometry, potentiometry, field-effect transistors (FETs), conductometry [21]). A Spanish team worked on the detection of different families of antimicrobial residues in milk by amperometric detection [22-24] and finally succeeded to develop a multiplex immunosensor for the detection of three families of antimicrobials simultaneously [25]. They obtained very promising results regarding the sensitivity of the developed methods. This immunosensor is based on the binding of antibodies against the antimicrobial residue to magnetic beads. Then the analyte (i.e., The antimicrobial residue) competes with the Horseradish peroxidase (HRP)-conjugate (HRP bound to the analyte) for the binding to the antibodies. At the end, the electrochemical activity of the enzyme HRP is measured by amperometry on Screen-printed carbon electrodes (SPCE). The concentration of antimicrobial residues is inversely proportional to the electrochemical signal because it a competitive immunoassay. The aim of this work was to develop a simialr bead-based amperometric immunosensor for the detection of chloramphenicol in honey.

The aim of this work will be to develop and to optimise an amperometric biosensor for the detection of CAP in honey. The project consisted into two steps: optimisation of the sensor and then development of an extraction protocol for honey samples to remove matrix interferences. The first results in buffer with simple amperometric conditions were very promising and satisfactory, as well as preliminary results in one single acacia honey sample. Different extraction protocols (liquid/liquid extraction (LLE)) were tested to obtain an optimal detection capability, at or below $0.3 \mathrm{ng} / \mathrm{g}$ (CAP MRPL). When analysing honey samples from different botanical origins, with different colours and textures, high matrix effects were observed. Regarding each individual sample, it was possible to discriminate blank samples from samples spiked with CAP to $0.3 \mathrm{ng} / \mathrm{g}$. However a global analysis was impossible due to the high variability of honey samples and to high matrix interferences. WE started to explore some paths to solve this issue but a lot of work is remaining.

\section{Materials and Methods}

\subsection{Antibiotic Standards}

Chloramphenicol (CRM) (CAS \#: 56-75-7) purchased from Sigma Aldrich (Saint-Quentin Fallavier, France). (Dr. Ehrenstorfer $\mathrm{GmbH}$, reference 56-75-7).

\subsection{Reagents}

All buffer solutions were prepared with Milli- ${ }^{\circledR}$ water. The PBS at $\mathrm{pH} 7.5$ contained $0.01 \mathrm{M}$ of phosphate buffer, $137 \mathrm{mM}$ of $\mathrm{NaCl}$ (Acros Organics, reference 207790010) and $2.7 \mathrm{mM}$ of KCl (Merck Chemicals, 104936). The PBS-T was derived from this PBS solution, to which was added $0.05 \%$ of Tween 20 (Sigma Aldrich, France, P1379). The phosphate buffer solutions at $0.05 \mathrm{M} \mathrm{pH} 6.0$ and $0.1 \mathrm{M}$ pH 6.0 were prepared from Na2HPO4, $2 \mathrm{H}_{2} \mathrm{O}$ (Labosi, Fisher Scientific A4894351) and $\mathrm{NaH}_{2} \mathrm{PO} 4$ (Merck, 1.06345.1000).

Hydrogen peroxide $\left(\mathrm{H}_{2} \mathrm{O}_{2}\right)$ (Sigma Aldrich, France, reference H-0904) and hydroquinone (Sigma Aldrich, France, reference H9003) were prepared in phosphate buffer.

The antibody anti-chloramphenicol (reference PAS 9681) and the conjugate CAP-HRP (reference HRP9263) were purchased from Randox Life Sciences (United Kingdom).

Magnetic beads (MBs) Protein G InVitrogen Dynabeads ${ }^{\circledR}$ (reference 10003D) were purchased from ThermoFischer Scientific (France). The magnetic beads contain proteins $G$ on their surface that facilitate the immobilisation of antibodies by their Fc parts.

Poly(vinylpolypyrrolidone) (PVPP) was purchased from Sigma Aldrich (France, reference 77627). 


\subsection{Preparation of Spiked Honey}

Honeys from different floral origins and from different suppliers have been collected. These honey samples have already been tested for the presence of antimicrobial residues with AM I and AM II kits (Randox, UK) with the Evidence Investigator ${ }^{\mathrm{TM}}$ system.

A stock solution of CAP at $1 \mathrm{mg} / \mathrm{mL}$ was prepared in methanol and stored at $-20{ }^{\circ} \mathrm{C}$ for 1 year. Then the stock solution was diluted to prepare spiking solutions at different concentrations. Spiking working solutions were prepared day-to-day. The final dilution in honey was always performed by adding $50 \mu \mathrm{L}$ of spiking solution to $1 \mathrm{~g}$ of honey.

\subsection{Materials}

The potentiostat (STAT300) supplied by Methrom (Switzerland) was connected via USB to a computer installed with Dropview 8400 software (Methrom, Switzerland).

Magnetic rack magnetic support (reference MAGNET16TUBE05) was purchased from DropSens (Spain). The thermoshaker (reference TS-100) was commercialised by BioSan (France).

Non modified Screen Printed Carbon Electrodes (SPCE) (reference DRP-110) and SPCE modified with Carboxyl functionalised Multi-Walled Carbon Nanotubes (MWCNT-COOH) (110CNT) were purchased from Methrom, Switzerland. An SPCE consists of a ceramic substrate incorporating the electrochemical cell. DRP-110 electrodes consisted in a working (4 mm diameter) and counter electrodes made of carbon, reference electrode is in silver. 110CNT consisted in a working electrode (4 mm diameter) made of Multi-Walled Carbon Nanotubes (MWCNT), counter electrode is made of carbon, whereas reference electrode and electric contacts are made of silver.

\subsection{Sample Preparation for Analyses}

Different extraction procedures of honey samples have been tested to find the optimized procedure. These different procedures will be presented shortly with the results.

\subsection{Assay Protocol}

The method's general principle was based on immuno-competition between CAP-HRP conjugate and the antimicrobial present (or not) in the sample for the binding to antibodies $(\mathrm{Ab})$ pregrafted onto magnetic beads (Figure 1). If there was no CAP in the sample (blank sample), the conjugate was able to bind to the antibody, and so a large quantity of HRP could react with $\mathrm{H}_{2} \mathrm{O}_{2}$ during the electrochemical reaction, thus generating a large amperometric signal. On the other hand, if CAP was present in the sample, there was a competition between CAP and HRP-conjugate, therefore less CAP-HRP was bound to Ab-MBs, and the amperometric signal decreased.

Three $\mu \mathrm{L}$ of beads were rinsed twice with PBS to remove the sodium azide preservative, then the supernatant was separated from the beads using a magnetic support that retains the beads on the walls of the tubes. These beads were then placed in contact with $50 \mu \mathrm{L}$ of antibodies. The antibodies were grafted in a thermoshaker for $30 \mathrm{~min}$ at $37^{\circ} \mathrm{C}$ and at $1200 \mathrm{rpm}$. Then the beads were washed twice in PBS-T to remove any unbound antibodies. Fifty $\mu \mathrm{L}$ of the mix of PBS-T (or a CAP solution or honey sample) with CAP-HRP conjugate were added to the tube. While the incubation was taking place, a solution of hydroquinone ( $275 \mathrm{mg}$ to $25 \mathrm{~mL}$ phosphate buffer) was prepared in phosphate buffer, as well as a solution of hydrogen peroxide ( $520 \mu \mathrm{L}$ to $5 \mathrm{~mL}$ of phosphate buffer). After incubation, the beads were rinsed twice with PBS-T $(100 \mu \mathrm{L})$ to remove compounds in excess that are not attached to the antibodies and the honey extract. Pending reading of the results, the beads were set aside in $50 \mu \mathrm{L}$ of phosphate buffer. The $50 \mu \mathrm{L}$ of magnetic beads were then deposited on the electrode, which itself was attached to a magnetic support, which was plunged into an electrochemical cell containing $12 \mathrm{~mL}$ of phosphate buffer and $1300 \mu \mathrm{L}$ of hydroquinone solution. Hydroquinone acts as an electron transducer to facilitate the redox reaction of hydrogen peroxide catalysed by HRP. Electrons will be taken up by the hydroquinone, and therefore be taken up by the electrode and this signal will be converted to a readable signal by the computer (Figure 2). A known 
potential $(-0.25 \mathrm{~V})$ was applied to the electrode and when a well-stabilised baseline appeared on the screen, $65 \mu \mathrm{L}$ of $\mathrm{H}_{2} \mathrm{O}_{2}$ solution was added (Figure 3).

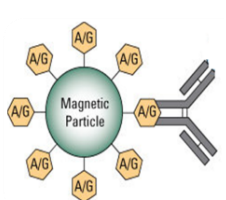

Ab grafting (1st incubation)

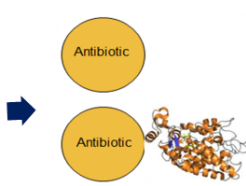

Addition of sample and HRP-conjugate ( $2^{\text {nd }}$ incubation)

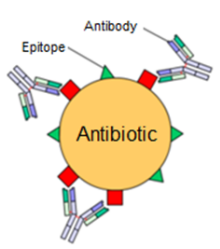

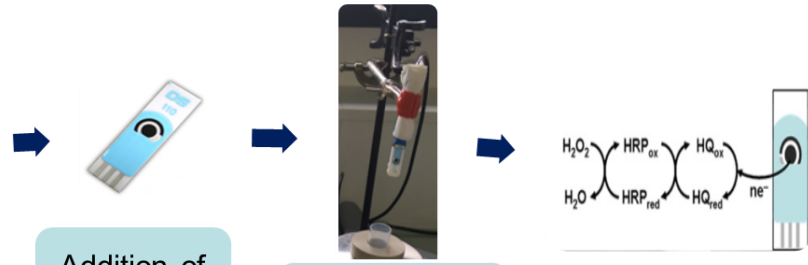

Addition of the mixture onto the electrode

\section{Dipping into} buffer + hydroquinone)

Horseradish peroxidase

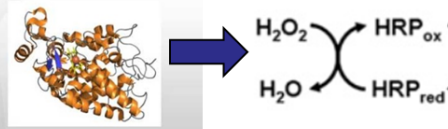

\section{Apply a potential $=>$ Read the result}

Figure 1. Principle of the disposable amperometric magneto-immunosensor for competitive detection of antimicrobial residues.

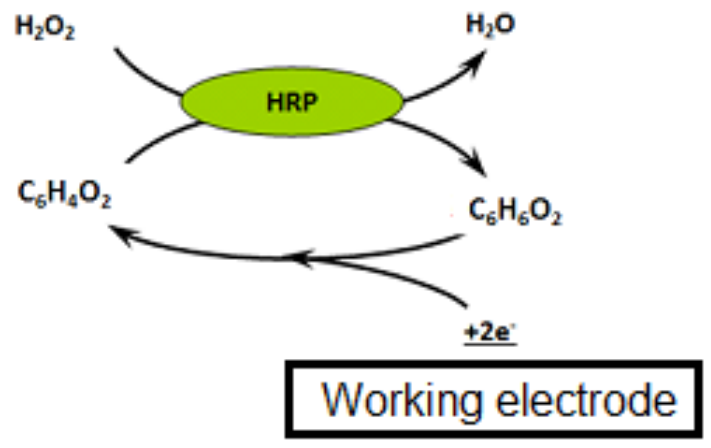

Figure 2. The electrochemical reaction at the working electrode.

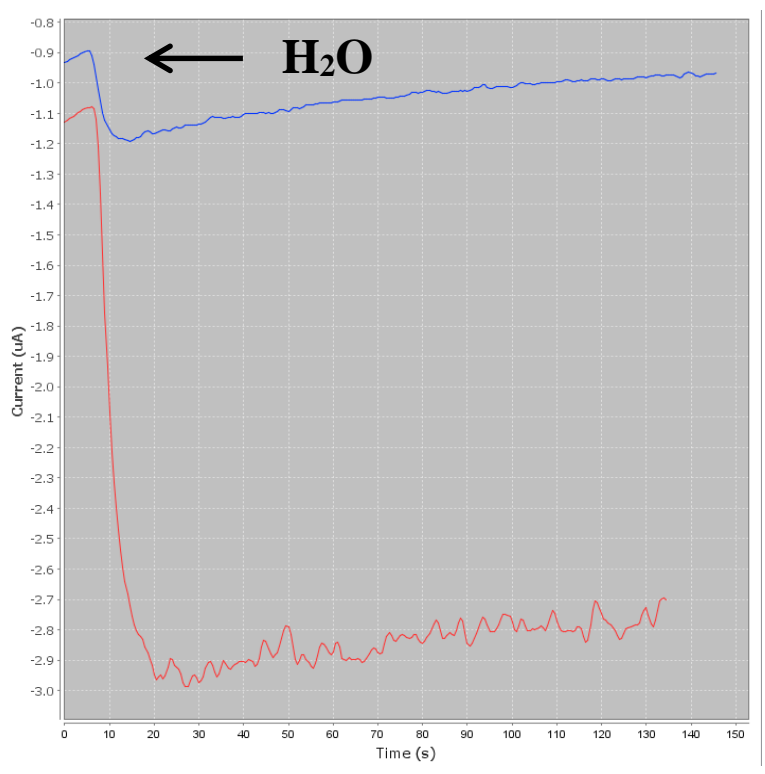

Figure 3. Measurement of the amperometric signal. Difference in signal between a blank sample (red) and a sample spiked to $10 \mathrm{ng} / \mathrm{mL}$ of chloramphenicol (blue) after addition of $\mathrm{H}_{2} \mathrm{O}_{2}$. 


\subsection{Optimisation of Assay Conditions}

Before starting the optimisation, the first test was carried out with a moderate quantity of beads $(5 \mu \mathrm{L})$ and a high concentration of antibodies and conjugate, in PBS-T. Then the assay conditions were optimised in buffer with a CAP concentration of $10 \mathrm{ng} / \mathrm{mL}$.

The aim of optimisation is to determine the technical conditions that is a compromise between sensitivity (limit of detection, at least less than or equal to the regulatory limit), and cost of analysis. Several steps in the method have been optimised (Table 1): quantity of magnetic beads, temperature, time and intensity of rotation for the antibody incubation with the beads, CAP-HRP conjugate, hydroquinone and hydrogen peroxide concentrations, incubation methods (i.e., a single incubation or a sequential incubation). Lastly, it is possible to adjust the potential applied by the potentiometer (between -0.1 and $-0.4 \mathrm{~V}$ ). 
Table 1. Summary of experimental conditions for optimising the screening method.

\begin{tabular}{|c|c|c|c|c|c|c|c|c|c|c|}
\hline Test Conditions & Test 1 & Test 2 & Test 3 & Test 4 & Test 5 & Test 6 & Test 7 & Test 8 & Test 9 & Test 10 \\
\hline Tested samples & 4 blank & \multicolumn{9}{|c|}{2 blank samples and 2 samples spiked to $10 \mathrm{ng} / \mathrm{mL}$} \\
\hline Beads $(\mu \mathrm{L})$ & 1 & $1,2,3,4$ & 3 & 3 & 3 & 3 & 3 & 3 & 3 & 3 \\
\hline [Antibodies] (dilution) & $\begin{array}{l}1 / 10,1 / 25 \\
1 / 50,1 / 100\end{array}$ & $1 / 50$ & $1 / 50$ & $1 / 50$ & $1 / 50$ & $1 / 50$ & $1 / 50$ & $1 / 50$ & $1 / 50$ & $1 / 50$ \\
\hline Incubation time (min) & 30 & 30 & $\begin{array}{c}10,20 \\
30,60\end{array}$ & 30 & 30 & 30 & 30 & 30 & 30 & 30 \\
\hline [HRP] (dilution) & $1 / 100$ & $1 / 100$ & $1 / 100$ & $\begin{array}{c}1 / 50,1 / 100 \\
1 / 250 \\
1 / 500\end{array}$ & $1 / 100$ & $1 / 100$ & $1 / 100$ & $1 / 100$ & $1 / 100$ & $1 / 100$ \\
\hline Incubation time (min) & 30 & 30 & 30 & 30 & $\begin{array}{c}10-20- \\
30-60\end{array}$ & 30 & 30 & 30 & 30 & 30 \\
\hline $\begin{array}{c}\text { Simultaneous (SI)/ } \\
\text { sequential (SE) }\end{array}$ & SI & SI & SI & SI & SI & SI/SE & SI & SI & SI & SI \\
\hline Eapp $(\mathrm{V})$ & -0.2 & -0.2 & -0.2 & -0.2 & -0.2 & -0.2 & $\begin{array}{l}-0.1,-0.2 \\
-0.3,-0.4 \\
\end{array}$ & -0.2 & -0.2 & -0.2 \\
\hline [Hydroquinone] (mM) & 1 & 1 & 1 & 1 & 1 & 1 & 1 & $\begin{array}{c}0.5,1,2.5 \\
5 \\
\end{array}$ & 1 & 1 \\
\hline$\left[\mathrm{H}_{2} \mathrm{O}_{2}\right](\mathrm{mM})$ & 100 & 100 & 100 & 100 & 100 & 100 & 100 & 100 & $\begin{array}{l}50,100, \\
250,500 \\
\end{array}$ & 100 \\
\hline
\end{tabular}




\subsection{Optimisation of Honey Extraction}

Once the method has been optimised in terms of the buffer, different extraction protocols from the bibliography were tested that will be detailed in the results part.

- Dilution in water or buffer,

- Extraction with acetonitrile and reconstitution in ultrapure water,

- Dilution in buffer, then extraction with ethyl acetate and reconstitution in buffer,

- Dilution in deionized water, then extraction with ethyl acetate to be repeated 3 times and reconstitution in buffer,

- Dilution in buffer (PBS). then extraction with ethyl acetate repeated 3 times and reconstitution in buffer.

\subsection{Data Analysis}

The intensity of the current was measured. Each day of analysis, mean, standard deviation (SD) and coefficient of variation (CV\%) were calculated for a set of identical samples (blank or spiked samples). Then a statistical approach which took into account the $\beta$ error of $5 \%$ was chosen as it was recommended in the European guideline for the validation of screening methods for veterinary drug residues [26].

The positivity threshold T (1) and the cut-off value Fm (2) were calculated.

$$
\mathrm{T}=\mathrm{B}-1.64 \times \mathrm{SDB}
$$

where: $B$ is the mean and SDB the standard deviation of the signal (RLU) of the blank samples.

$$
\mathrm{Fm}=\mathrm{M}+1.64 \times \mathrm{SD}
$$

where: $\mathrm{M}$ is the mean and SD the standard deviation of the signal (RLU) of the spiked samples.

The assay was considered valid only if $\mathrm{T}$ was higher than $\mathrm{Fm}$.

\section{Results}

\subsection{Measures in Buffer before Optimisation}

A range of samples was prepared in PBS-T with four different concentrations of chloramphenicol, in order to assess the potential of this method: blanks, $1 \mathrm{ng} / \mathrm{mL}, 10 \mathrm{ng} / \mathrm{mL}$ and 100 $\mathrm{ng} / \mathrm{mL}$, with three replicates per condition. The results presented in Figure 4 showed that the spiked samples were clearly discriminated from the blank samples. Furthermore the spiked samples can be differentiated from each other according to their concentration. Following these encouraging results, we decided to test optimise the assay. 


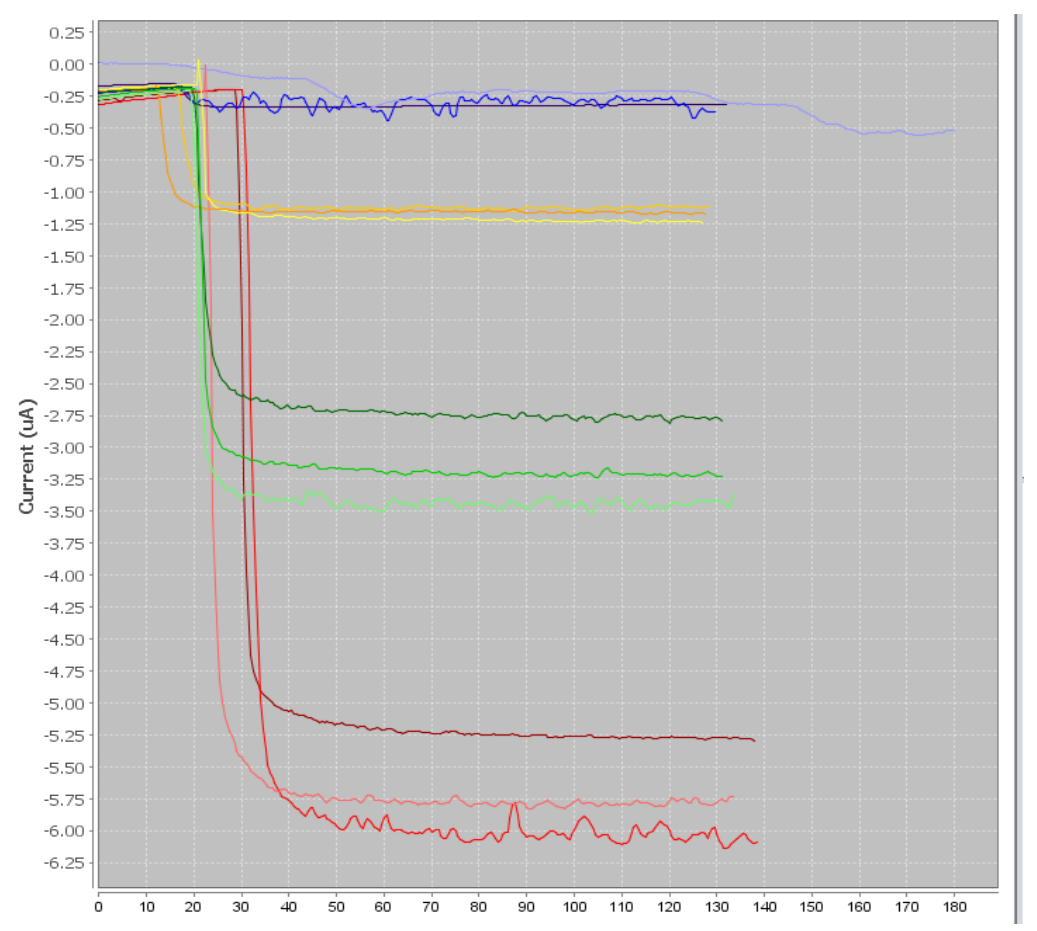

Figure 4. Graph showing a series of spiked solutions of chloramphenicol in PBS-T. The red curves represent blank samples, in green the samples spiked to $1 \mathrm{ng} / \mathrm{mL}$, orange to $10 \mathrm{ng} / \mathrm{mL}$ and blue to 100 $\mathrm{ng} / \mathrm{mL}$.

\subsection{Optimisation of Assay Condtions in Buffer}

Some results of the optimisation of some parameters are displayed as examples in Figure 5. The first tested parameter was the dilution of the antibody (Figure 5a), bearing in mind that it had already previously been diluted to $1 / 10$ th. For this condition, we only used the blank samples, in order to watch the signal fall. The optimal dilution was $1 / 10$ th in terms of the signal height (the greater the signal, the more sensitive the method); however, in order to reduce the experimental costs and because the signal from the blanks was sufficiently strong, a dilution to $1 / 50$ th was selected. For the other parameters, the measured current obtained after analyses of blank samples (orange) and samples spiked to $10 \mathrm{ng} / \mathrm{mL}$ (green) were compared. The second tested parameter was the quantity of magnetic beads per tube. The more beads there are, the more antibodies can be immobilised, thereby increasing the signal. When the quantity of beads is lowered, the signal would decrease, but also the beads could be saturated with antibodies, without overspending. Generally, a range from 1 to $10 \mu \mathrm{L}$ of beads per tube is tested. The graph shows an optimal quantity between 3 and $4 \mu \mathrm{L}$ (Figure $5 b)$; the optimisation continued with $3 \mu \mathrm{L}$ of beads per tube for economic reasons. 
(a)

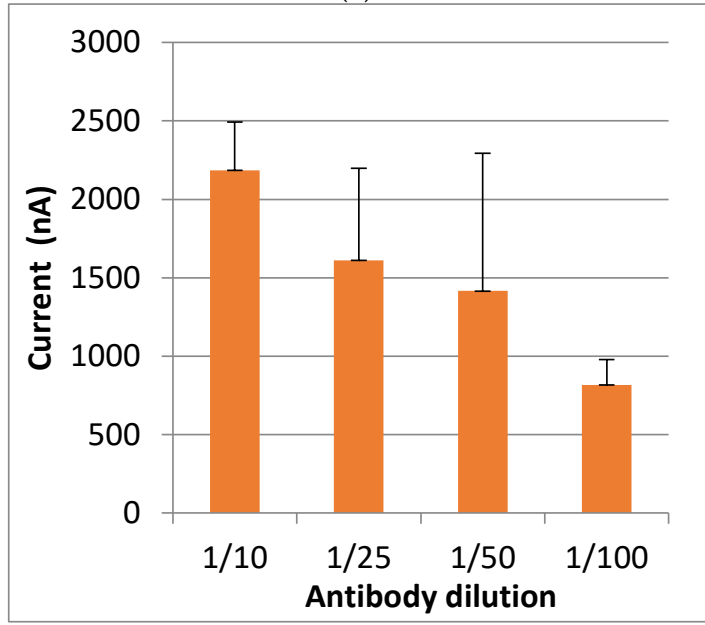

(c)

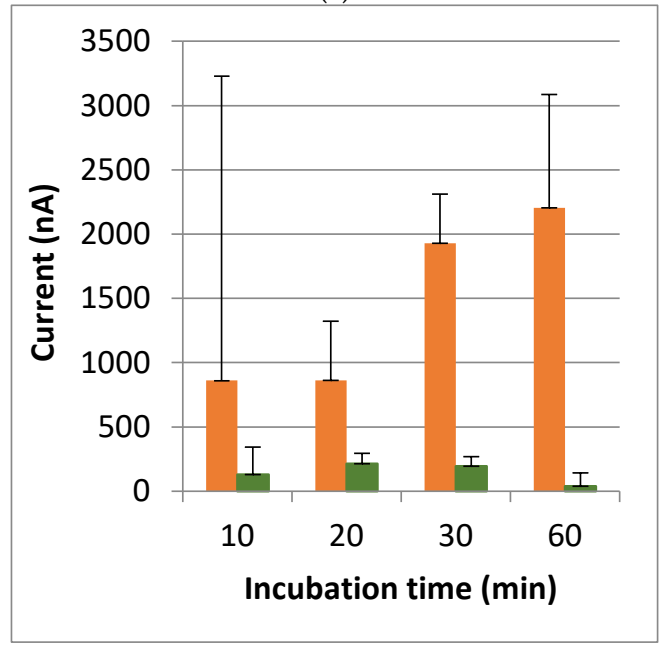

(e)

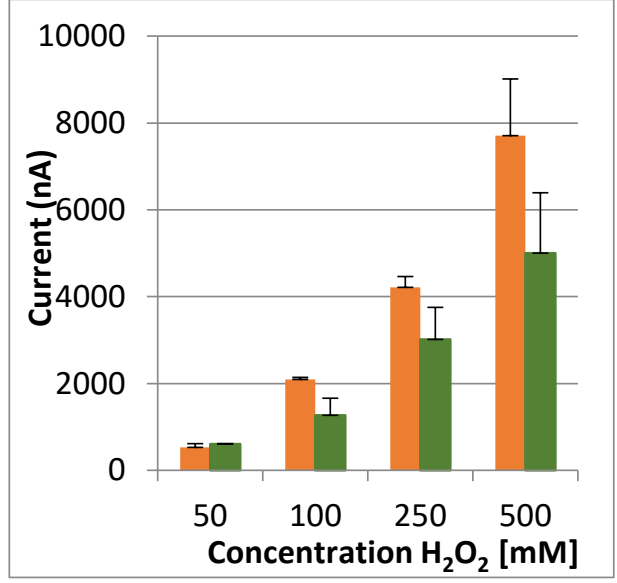

(b)

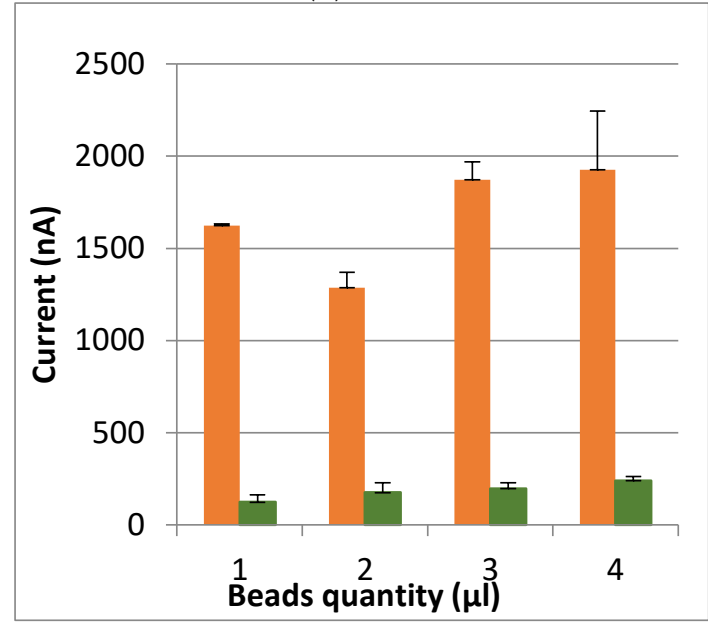

(d)

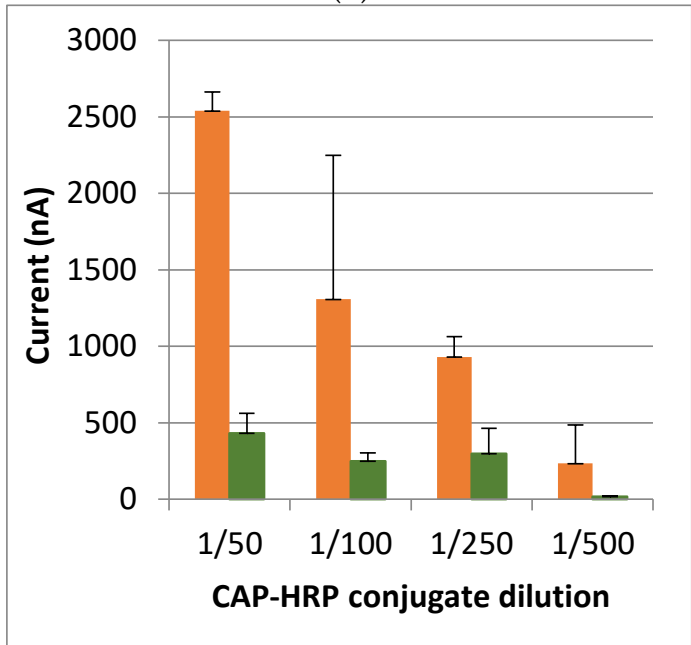

(f)

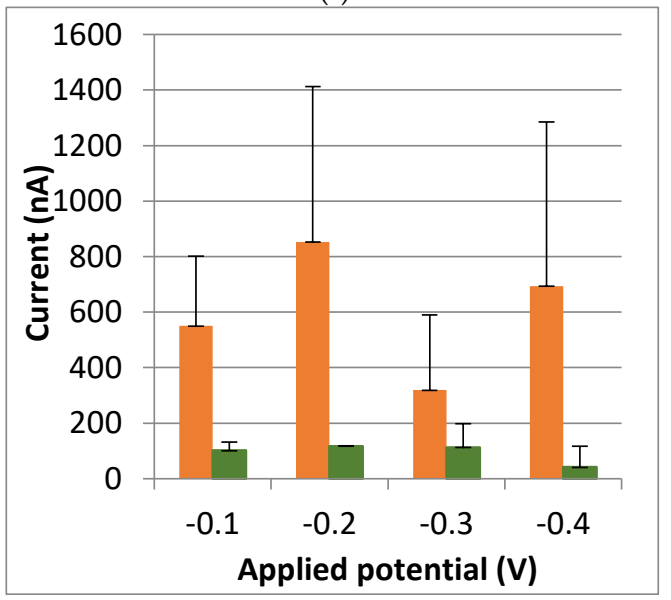

Figure 5. Results of optimisation of different technical parameters: influence on the current measurement. (a) Graph showing the current (nA) as a function of the dilution of antibodies used in the blank samples; (b) Graph showing the current (nA) as a function of the quantity of beads used $(\mu \mathrm{L})$ in the blank (orange) or spiked (green) samples; (c) Graph showing the current (nA) as a function of the incubation time of the antibody with the magnetic beads, in the blank (orange) or spiked (green) samples; (d) Graph showing the current (nA) as a function of the dilution of the CAP-HRP, in the blank (orange) or spiked (green) samples; (e) Graph showing the current (nA) as a function of the concentration of $\mathrm{H} 2 \mathrm{O} 2$, in the blank (orange) or spiked (green) samples; (f) Graph showing the current (nA) as a function of the applied potential, in the blank (orange) or spiked (green) samples. 
The incubation time needed for the antibodies to be grafted onto the magnetic beads is a crucial parameter for optimal binding. The tested times were 10, 20, 30 and $60 \mathrm{~min}$ (Figure 5c). The time selected was a compromise between sensitivity and rapidity of the assay. The selected optimal time was 30 min because it seemed sufficient to obtain discrimination in signal between blank and spiked milk samples.

The CAP-HRP was previously diluted to $1 / 10$ th. The graph presented in Figure $5 \mathrm{~d}$ shows that the optimal dilution was $1 / 50$ th, When the conjugate concentration was increased, a signal produced was maximum because all the free antibody paratopes may be occupied. However, the competition with CAP could be too strong. However a dilution to $1 / 100$ th was selected because the current obtained was sufficiently high and the cost of analysis was reduced.

Two types of incubation were tested:

- a single incubation, i.e., the antibodies bound to beads were in contact with both CAP and CAPHRP,

- $\quad$ a sequential incubation, i.e., the antibodies bound to beads were initially put in the presence of CAP alone, and then halfway through the planned incubation time, the CAP-HRP conjugate was added. Therefore the antibodies had time to bind with CAP before any competition with the conjugate took place. It was hypothesised that the difference in signal between the blank samples (conjugate alone) and the spiked ones (conjugate and CAP) may increase.

Two incubation times (30 and $60 \mathrm{~min}$ ), according to two incubation methods (simultaneous and sequential) were tested. The results seemed equivalent (data not shown). However, when looking at the curves, the results were highly variable for 10 and $20 \mathrm{~min}$. The selected incubation method was the simultaneous method, for an incubation time of $30 \mathrm{~min}$.

We subsequently observed the effects of different concentrations of hydroquinone and $\mathrm{H}_{2} \mathrm{O}_{2}$. It was observed that the higher the concentration of hydroquinone, the smaller the signal difference between the blank and spiked samples (data not shown). We assumed that if the concentration of hydroquinone was increased without increasing that of $\mathrm{H}_{2} \mathrm{O}_{2}$, the signal difference between the blank and spiked samples would also have been smaller. Therefore the highest concentration of hydroquinone $(5 \mathrm{mM})$ was selected. Then increasing concentrations of $\mathrm{H}_{2} \mathrm{O}_{2}$ were tested. The results presented in Figure 5e clearly show that a higher concentration of $\mathrm{H}_{2} \mathrm{O}_{2}$ yields stronger signals, while retaining a noticeable difference between the blank and spiked samples. We also compared two combinations of hydroquinone $/ \mathrm{H}_{2} \mathrm{O}_{2}\left(5 \mathrm{mM} / 500 \mathrm{mM}\right.$ and $\left.1 \mathrm{mM} / \mathrm{H}_{2} \mathrm{O}_{2} 1 \mathrm{M}\right)$ (data not shown). As the difference in signal was even greater, we therefore decided to continue with this last combination (1 $\mathrm{mM} / \mathrm{H}_{2} \mathrm{O}_{2} 1 \mathrm{M}$ ).

Lastly, the potential applied by the potentiometer was adjusted between -0.1 and $-0.4 \mathrm{~V}$. The applied potential, $-0.2 \mathrm{~V}$, obtained the best signals and the best discrimination between the blank and spiked milks (Figure $5 \mathrm{f}$ ).

These different experiments enabled us to determine the optimal conditions for detecting samples of milk spiked with chloramphenicol to $10 \mathrm{ng} / \mathrm{mL}$ :

- $3 \mu \mathrm{L}$ of beads per tube

- Antibodies diluted to $1 / 50$ th and incubated for $30 \mathrm{~min}$

- CAP-HRP diluted to $1 / 100$ th and incubated for $30 \mathrm{~min}$ with the sample (i.e., simultaneous method)

- Hydroquinone concentration of $1 \mathrm{mM}$ and $\mathrm{H} 2 \mathrm{O} 2$ of $1 \mathrm{M}$

- $\quad$ Applied potential of $-0.2 \mathrm{~V}$ 


\subsection{Optimisation of Honey Extraction}

\subsubsection{Honey Dilution}

We first diluted one sample of acacia honey in ultrapure water at $1 / 4,1 / 5$ and $1 / 10$. Firstly, there was a decrease of the signal with the increased concentrations of CAP that was satisfactory (Figure 6). The current produced by the analysis of blank and spiked samples was higher when the sample was the more diluted $(1 / 10)$ but the sensitivity is decreased. However we observed a high variability on the measured current (around 20\%), taking into account that it is a single acacia honey sample that was analysed several times. When there is no error bars, the sample was analysed only once. Threshold value T was calculated for dilution 1/5 at 822 and the cut-off Fm at $903 \mathrm{nA}$ because of the variability. The assay failed because $\mathrm{T}$ is lower than $\mathrm{Fm}$ value. Regarding the high standard deviations at $3 \mathrm{ng} / \mathrm{g}$, we assumed that the detection capability of the method would not be low enough to detect CAP below $0.3 \mathrm{ng} / \mathrm{g}$.

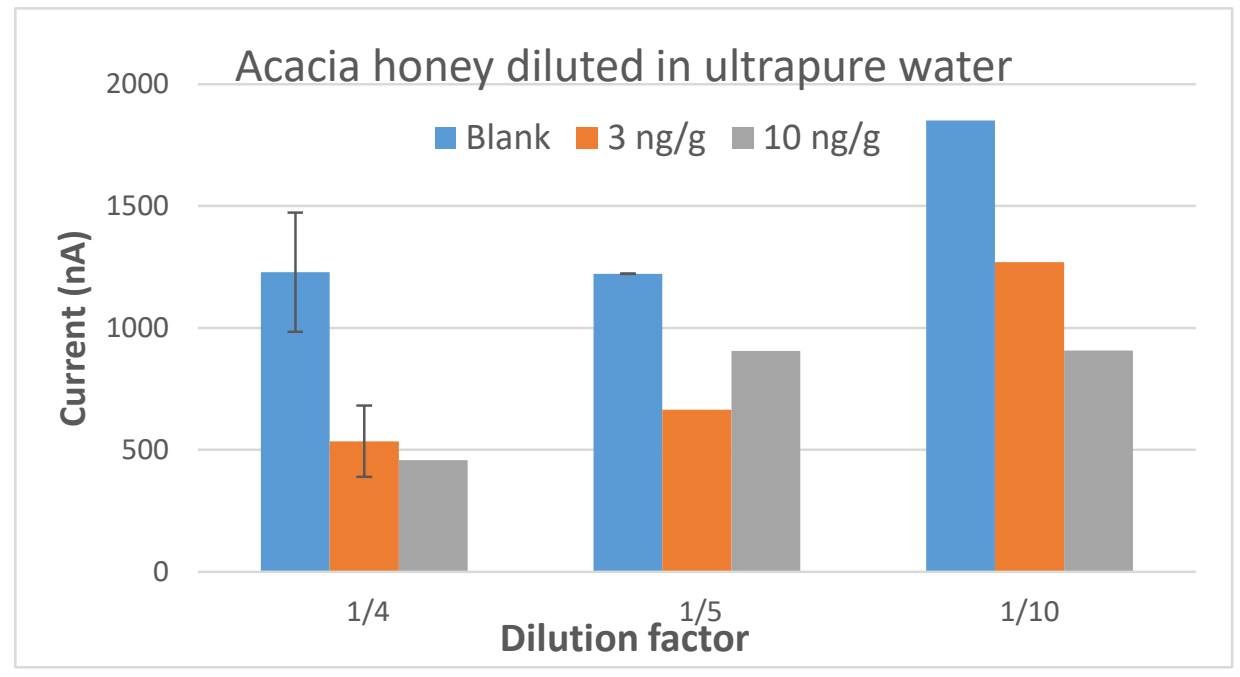

Figure 6. Analysis of one blank acacia honey sample, spiked to 3 and $10 \mathrm{ng} / \mathrm{g}$ of CAP, before dilution in ultrapure water at different concentrations.

\subsubsection{Measurement of $\mathrm{pH}$ of Diluted Honey}

It was assumed that the $\mathrm{pH}$ of honey could influence the capability of detection of the amperometric biosensor. Indeed the honeys are known to be all acidic and the nectar honeys generally have a $\mathrm{pH}$ of between 3.5 and 4.5. Therefore, the $\mathrm{pH}$ of honey samples from different botanical origins was determined, after the dilution of honey samples at 1/10th in different solutions (water, PBS pH 7.5, PBS-T pH 7.5 and phosphate buffer pH 6.0) (Figure 7). 


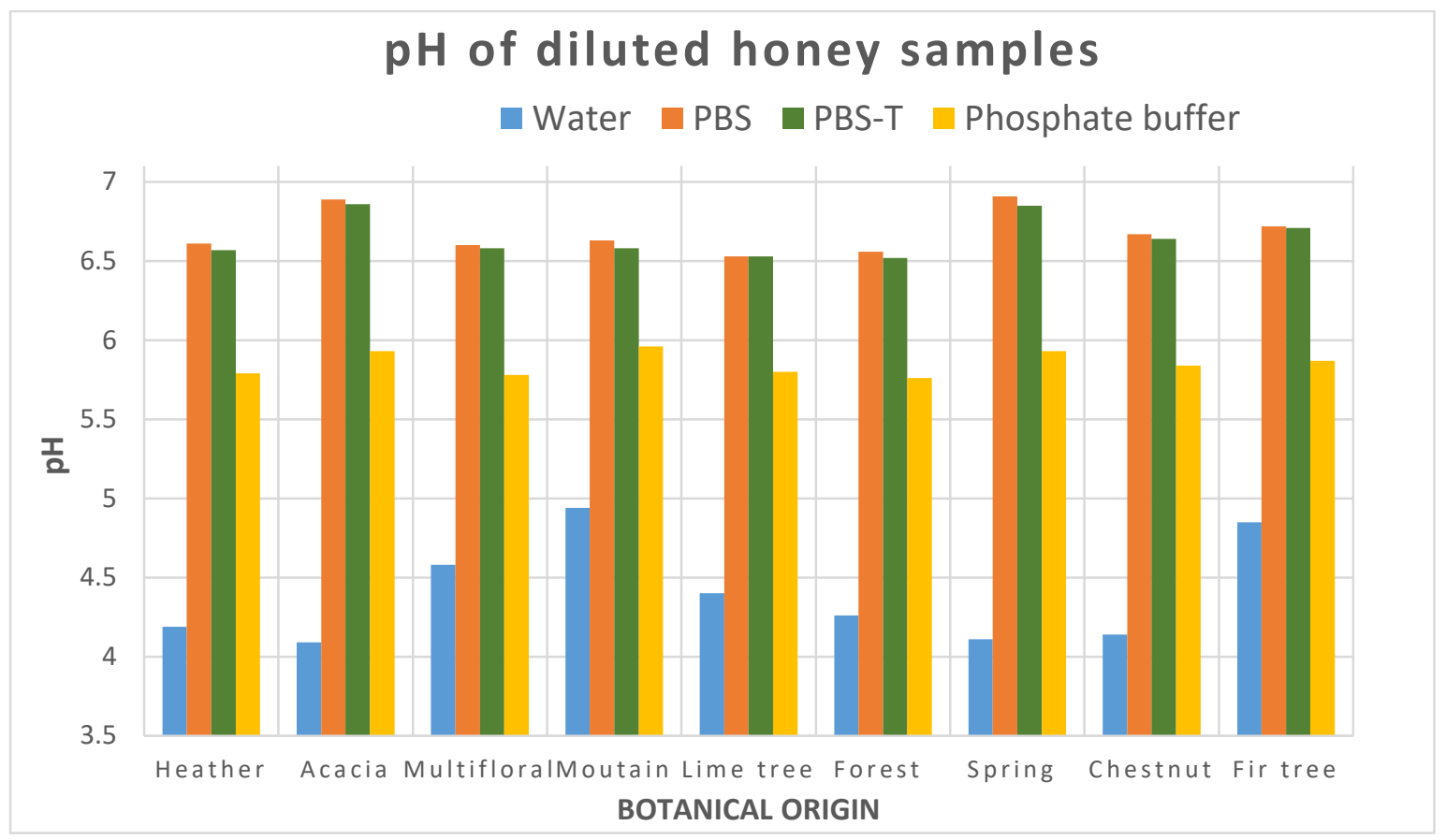

Figure 7. Measurement of $\mathrm{pH}$ of honey samples depending on the buffer used for dilution and to the botanical origin of honey.

Figure 8 shows that dilution in ultrapure water led to different $\mathrm{pH}$ values between 4.0 and 5.0, depending on the botanical origin of honey samples. Water do not have a buffering effect. On the contrary, the three buffers performed well their buffering function. The $\mathrm{pH}$ were included between 6.5 to 7.0 for PBS and PBS-T and between 5.5 to 6.0 for phosphate buffer. These results suggested that the $\mathrm{pH}$ of honey is not responsible for the high variability of the results because of the buffering effect after dilution in buffers.

Then a dilution of the acacia honey sample was tested at 1/10th in $0.1 \mathrm{M}$ PBS pH 7.0 by stirring for $20 \mathrm{~min}$. The T value (4499) was lower than the Fm value calculated at $1 \mathrm{ng} / \mathrm{g}$ (4395) (failed), but higher than Fm at $3 \mathrm{ng} / \mathrm{g}$ (4303). However this last concentration is ten times higher than the target concentration (MRPL $=0.3 \mathrm{ng} / \mathrm{g}$ ). Therefore the method was not enough sensitive. The dilution was abandoned to test extraction protocols, as it is performed with classical analytical method (e.g., ELISA, LC-MS/MS). 


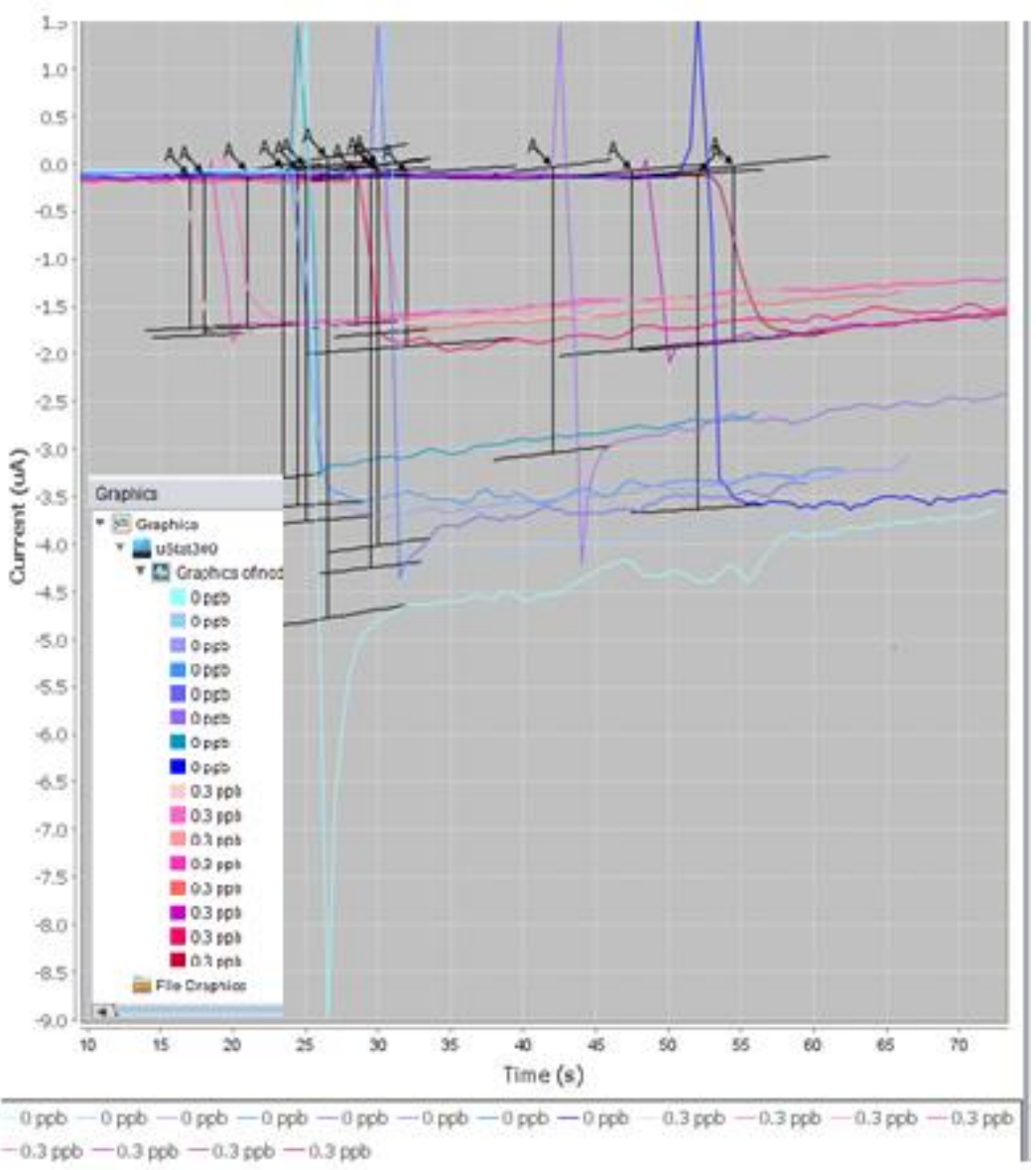

(a)

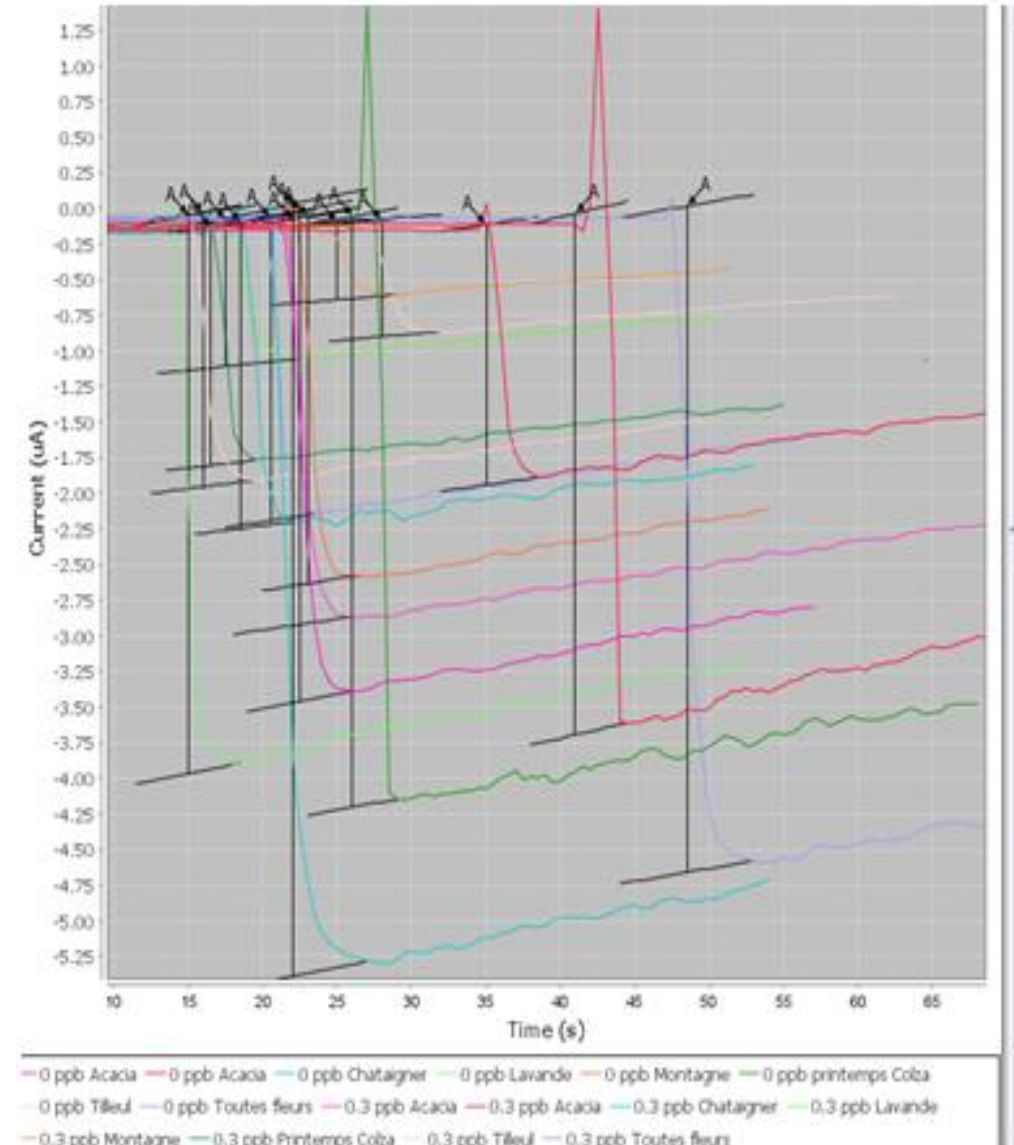

(b)

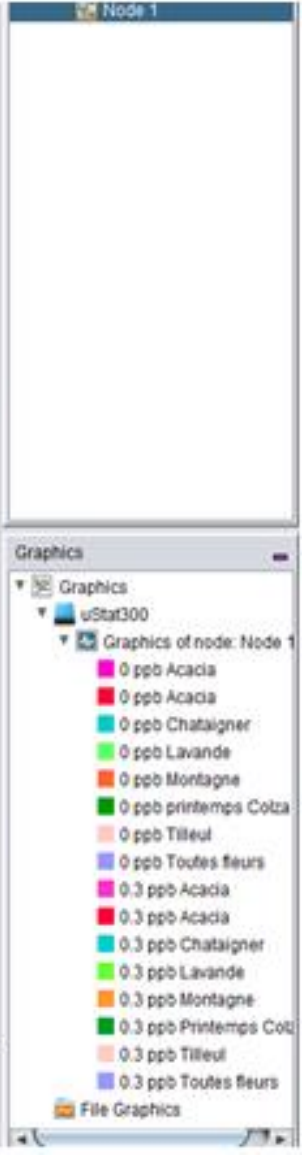

Figure 8. Comparison of amperometric curves when analysing one single acacia honey and when analysing honey samples from different botanical origins. (a) Results of repeated extractions and analyses of one single acacia honey. (b) Analyses of eight honey samples from different botanical origins. 


\subsubsection{Honey Extraction}

Extraction with Acetonitrile and Reconstitution in Ultrapure Water

$1.0 \mathrm{~g}$ of acacia honey sample was treated with $3 \mathrm{~mL}$ of acetonitrile. The mixture was vortexed for $2 \mathrm{~min}$ and sonicated for $30 \mathrm{~min}$, then centrifuged at $5000 \mathrm{rpm}$ for $7 \mathrm{~min}$. The supernatant was collected in a glass tube and then was evaporated to dryness at $50^{\circ} \mathrm{C}$ under nitrogen stream. The obtained extracts were reconstituted with $200 \mu \mathrm{L}$ of ultrapure water.

The $\mathrm{T}$ value (2495) (4 repetitions) was higher than the Fm value calculated at $1 \mathrm{ng} / \mathrm{g}$ (1807) (3 repetitions), and obviously higher than Fm at $3 \mathrm{ng} / \mathrm{g}$ (1296) (3 repetitions). Therefore this assay was very satisfactory and promising.

Then the protocol was only modified by adding a heating step at $40^{\circ} \mathrm{C}$ for $15 \mathrm{~min}$ before adding $3.0 \mathrm{~mL}$ of acetonitrile. Finally, the extracts were reconstituted in ultrapure water, in PBS-T or in phosphate buffer. The analysis of the acacia honey samples in the different conditions was repeated 2 to 3 times. The Fm value was calculated from the results of samples spiked with CAP to $1 \mathrm{ng} / \mathrm{g}$ (Table 2). After the reconstitution in water, the results were not satisfactory $(T>F m)$ while reconstitution in PBS-T and phosphate buffer gave satisfactory results at $1 \mathrm{ng} / \mathrm{g}$.

Table 2. Comparison of threshold $\mathrm{T}$ and cut-off Fm values when honey extracts were reconstituted in ultrapure water, PBS-T and phosphate buffer.

\begin{tabular}{ccccc}
\hline Volume of Reconstitution & & Water & PBS-T & Phosphate Buffer \\
\hline \multirow{2}{*}{$200 \mu \mathrm{L}$} & $\mathrm{T}^{1}$ & 1006 & 3823 & 6021 \\
\cline { 2 - 5 } & $\mathrm{Fm}^{1}$ & 5412 & 3350 & 4196 \\
\cline { 2 - 5 } & Assay & Not valid & Valid & Valid \\
\hline \multirow{2}{*}{$\mathbf{1 2 0} \boldsymbol{\mu L}$} & $\mathrm{T}^{1}$ & 3742 & 5940 & 6234 \\
\cline { 2 - 5 } & $\mathrm{Fm}^{1}$ & 3936 & 3004 & 3613 \\
\cline { 2 - 5 } & Assay & Not valid & Valid & Valid \\
\hline
\end{tabular}

${ }^{1} \mathrm{~T}$ and $\mathrm{Fm}$ are expressed in $\mathrm{nA}$.

\section{Ethyl Acetate Extraction}

After heating $1.0 \mathrm{~g}$ of acacia honey sample at $40{ }^{\circ} \mathrm{C}$ for $15 \mathrm{~min}$, honey samples were treated with $3 \mathrm{~mL}$ of ethyl acetate. The mixture was vortexed for $2 \mathrm{~min}$ and sonicated for $30 \mathrm{~min}$, then centrifuged at $5000 \mathrm{rpm}$ for $7 \mathrm{~min}$. The supernatant was collected in a glass tube and then was evaporated to dryness at $50{ }^{\circ} \mathrm{C}$ under nitrogen stream. The obtained extracts were reconstituted with $120 \mu \mathrm{L}$ of PBS$\mathrm{T}$. The same day, the extraction in acetonitrile was also performed to compare both protocols. Honey samples were spiked to 0.5 and $1 \mathrm{ng} / \mathrm{g}$. The results in acetonitrile were less satisfactory than the previous day, even if the assay was valid at $1 \mathrm{ng} / \mathrm{g}$. However the assay in acetonitrile failed at 0.5 $\mathrm{ng} / \mathrm{g}$ (Table 3). The assay in ethyl acetate was valid at both CAP concentrations. To improve the sensitivity of the assay, the volume of solvent was increased from $3 \mathrm{~mL}$ to $7 \mathrm{~mL}$. We could observe that the detection capability was better with $7 \mathrm{~mL}$ than with $3 \mathrm{~mL}$ for both acetonitrile and ethyl acetate extractions. The results were more repeatable with ethyl acetate. Therefore we decided to continue with this solvent.

Table 3. Comparison of threshold $\mathrm{T}$ and cut-off Fm values when $1.0 \mathrm{~g}$ of acacia honey was extracted in acetonitrile and ethyl acetate.

\begin{tabular}{ccccc}
\hline & \multicolumn{2}{c}{ Acetonitrile } & \multicolumn{2}{c}{ Ethyl Acetate } \\
\hline & $3 \mathrm{~mL}$ & $7 \mathrm{~mL}$ & $3 \mathrm{~mL}$ & $7 \mathrm{~mL}$ \\
\hline $\mathbf{T}^{\mathbf{1}}$ & 2907 & 4304 & 3656 & 5231 \\
\hline Fm (0.5 $\mathbf{~ g / g ) ~} \mathbf{1}^{\mathbf{A}}$ & 3816 & 3676 & 3329 & 3835 \\
\hline Assay & Not valid & Valid & Valid & Valid \\
\hline
\end{tabular}




\begin{tabular}{ccccc}
\hline Fm (1 $\mathbf{~ n g} / \mathbf{g})^{\mathbf{1}}$ & 2786 & 3384 & 2762 & nd \\
\hline Assay & Valid & Valid & Valid & $/$ \\
\hline
\end{tabular}

${ }^{1} \mathrm{~T}$ and Fm are expressed in Na. nd: not determined.

Then to improve the sensitivity of the assay, the weight of acacia honey was increased from 1.0 $\mathrm{g}$ to $2.0 \mathrm{~g}$. The extraction was performed with $3 \mathrm{~mL}$ and $7 \mathrm{~mL}$ of ethyl acetate for comparison. Honey samples were spiked to 0.3 and $0.5 \mathrm{ng} / \mathrm{g}$. The assay was repeated twice (two different days). The results were globally better with $7 \mathrm{~mL}$ of ethyl acetate, except the first day at $0.3 \mathrm{ng} / \mathrm{g}$ of CAP. This unsatisfactory result was due to high variability of the 3 replicates at this concentration (23.4\%) (Table $4)$.

Table 4. Comparison of threshold $\mathrm{T}$ and cut-off Fm values when $2.0 \mathrm{~g}$ of acacia honey was extracted with $3 \mathrm{~mL}$ and $7 \mathrm{~mL}$ of ethyl acetate.

\begin{tabular}{|c|c|c|c|c|}
\hline & \multicolumn{2}{|c|}{ Day 1} & \multicolumn{2}{|c|}{ Day 2} \\
\hline Volumes of Ethyl Acetate & $3 \mathrm{~mL}$ & $7 \mathrm{~mL}$ & $3 \mathrm{~mL}$ & $7 \mathrm{~mL}$ \\
\hline$T^{1}$ & 6667 & 6409 & 4846 & 4406 \\
\hline Fm $(0.3 \mathrm{ng} / \mathrm{g}){ }^{1}$ & 5100 & 6884 & 3984 & 2981 \\
\hline Assay & Valid & Not valid & Valid & Valid \\
\hline Fm $(0.5 \mathrm{ng} / \mathrm{g})^{1}$ & 4148 & 4460 & 2178 & 2790 \\
\hline Assay & Valid & Valid & Valid & Valid \\
\hline
\end{tabular}

${ }^{1} \mathrm{~T}$ and Fm are expressed in Na. nd: not determined.

The day after, five aliquots of $2.0 \mathrm{~g}$ of the same acacia honey sample were prepared and five aliquots of the same honey were spiked with CAP at $0.3 \mathrm{ng} / \mathrm{g}$. The 10 samples were extracted as described previously with $7 \mathrm{~mL}$ of ethyl acetate and reconstituted in $120 \mu \mathrm{L}$ of PBS-T. The threshold value $\mathrm{T}$ was equal to 2807 and the cut-off factor Fm to 1904; therefore, the assay was valid. The method was able to detect CAP at $0.3 \mathrm{ng} / \mathrm{g}$ in one sample of acacia honey.

Regarding these promising results, the same extraction protocol was applied to 8 different honey samples from different botanical origins, with different colours and textures (i.e., acacia (2 samples), chestnut, lavender, mountain, spring, lime tree, multifloral). The results were clearly different when honey samples from different botanical origins were analysed (Figure 8). When calculating the threshold value $T$ and the Fm value, the assay was not valid because T (1902) was lower than Fm (2905). This conclusion was logical because the coefficient of variation (CV) calculated on blank samples was $30 \%$ and $48 \%$ on spiked samples from different botanical origins. On the opposite, when only acacia samples were analysed, the CV on blank samples was equal to $16 \%$ and $7 \%$ on spiked samples. However, when looking at individual results for each honey sample, the discrimination between the signals (current (nA)) from the blank honey and the same sample spiked with CAP to $0.3 \mathrm{ng} / \mathrm{g}$ is clear. It was highlighted here than even with an extraction procedure in ethyl acetate, the honey matrix effect was always strong, impeding and preventing a global analysis for honey from different botanical origins.

Table 5. Results of the analyses of honey samples from different botanical origins after extraction of $2.0 \mathrm{~g}$ of honey in ethyl acetate $(7 \mathrm{~mL})$.

\begin{tabular}{cccccc}
\hline \multicolumn{7}{c}{ Current (nA) } \\
\hline Botanical Origin & Blank & CAP 0.3 ng/g & Botanical Origin & Blank & CAP 0.3 ng/g \\
\hline Acacia & 3444 & 2851 & Acacia & 3528 & 1594 \\
\hline Acacia & 3660 & 1828 & Acacia & 4000 & 1700 \\
\hline Chestnut & 5415 & 2153 & Acacia & 3008 & 1875 \\
\hline Lavender & 3917 & 1025 & Acacia & 3250 & 1818 \\
\hline Mountain & 2581 & 546 & Acacia & 3528 & 1841 \\
\hline Spring & 4146 & 1669 & & & \\
\hline
\end{tabular}




\begin{tabular}{ccc}
\hline Lime tree & 1924 & 820 \\
\hline Multifloral & 4676 & 2127 \\
\hline
\end{tabular}

Dilution in Ultrapure Water and Ethyl Acetate Extraction

To solve the issue with botanical origins, a new extraction protocol was tested, inspired by an internal procedure for the screening and confirmation of CAP by LC-MS/MS. One millilter of ultrapure water was added to $2.0 \mathrm{~g}$ of honey sample, then vortexed and kept in contact for $10 \mathrm{~min}$. Samples were treated with $6 \mathrm{~mL}$ of ethyl acetate. The mixture was vortexed for $2 \mathrm{~min}$ and stirred with rotary agitator for $10 \mathrm{~min}$, then centrifuged at $5000 \mathrm{rpm}$ for $5 \mathrm{~min}$. The supernatant $(5 \mathrm{~mL})$ was collected in a glass tube and then was evaporated to dryness at $50{ }^{\circ} \mathrm{C}$ under nitrogen stream. The obtained extracts were reconstituted firstly with $0.6 \mathrm{~mL}$ of iso-octane, vortexed and then $0.6 \mathrm{~mL}$ of water was added. The reconstituted extracts were gently mixed manually, centrifuged for $5 \mathrm{~min}$ at $50000 \mathrm{rpm}$. Finally $50 \mu \mathrm{L}$ of the lower phase were taken. This extraction procedure was not satisfactory at all. There was no discrimination between blank and spiked samples, even if each sample is taken individually (data not shown).

\section{Dilution in PBS and Ethyl Acetate Extraction}

The extraction protocol develop by Yan et al. [27] was tested with slight modifications to solve this issue. Blank honey samples from different botanical origins (i.e., acacia, chestnut, forest, mountain, spring, lime tree) and the same samples spiked with CAP to $0.3 \mathrm{ng} / \mathrm{g}$ were analysed during 2 days: One g of honey was mixed with $3 \mathrm{~mL}$ of PBS. A $4 \mathrm{~mL}$ of ethyl acetate was added and the samples were vortexed and centrifuged for $10 \mathrm{~min}$ at $4000 \mathrm{rpm}$. The supernatant was transferred to another tube. To enhance the extract efficiency, the extracting step for CAP was repeated three times. The collected supernatant was dried under nitrogen flow and then resuspended in $0.5 \mathrm{~mL}$ of phosphate buffer the first day and $1 \mathrm{~mL}$ of PBS the second day. In both cases, the threshold value T was lower than the cut-off Fm (data not shown). Therefore the assays were not valid. When looking at the results of individual honeys, there was a discrimination between blank and spiked samples, except for mountain honey (Table 6).

Table 6. Results of the analyses (measured current (nA)) of honey samples from different botanical origins after dilution of $1.0 \mathrm{~g}$ of honey with $3 \mathrm{~mL}$ of PBS and extraction in ethyl acetate $(4 \mathrm{~mL})$.

\begin{tabular}{ccccc}
\hline & \multicolumn{5}{c}{ Reconstitution in } \\
& $\mathbf{0 . 5} \mathbf{~} \mathbf{L}$ Phosphate Buffer & & $\mathbf{1 ~} \mathbf{~} L \mathbf{~ P B S}$ \\
\hline Botanical origin & Blank & CAP 0.3 ng/g & Blank & CAP 0.3 ng/g \\
\hline Acacia & 4629 & 3273 & 7438 & 6944 \\
\hline Chestnut & 2876 & 2390 & 4851 & 4314 \\
\hline Forest & 3266 & 3044 & $/$ & 6340 \\
\hline Mountain & 3071 & 3107 & $/$ & $/$ \\
\hline Spring & 3722 & 2992 & 7635 & 6830 \\
\hline Lime tree & 3519 & 2462 & 6954 & 4546 \\
\hline
\end{tabular}

Dilution in Water and Ethyl Acetate Extraction

A new protocol was tested inspired by Xiao et al. [28]. $1.0 \mathrm{~g}$ of honey was added into $3 \mathrm{~mL}$ of deionized water and vortexed for $5 \mathrm{~min}$. The mixture was centrifuged at $4000 \mathrm{rpm}$ for $10 \mathrm{~min}$ and the supernatant was extracted by $6 \mathrm{~mL}$ of ethyl acetate for three times. The collected supernatant was evaporated and mixed with $1 \mathrm{~mL}$ PBS ( $\mathrm{pH} 7.5$ ) by vortexing, and then filtered by a $0.22 \mu \mathrm{m}$ membrane filter. The final extract was diluted by 10 -fold PBS ( $\mathrm{pH} 7.5$ ). The threshold value $\mathrm{T}$ was lower than the cut-off Fm (data not shown). Therefore the assays were not valid. When looking at the individual honey results, blank and spiked samples could be discriminated (Table 7). The repetition of the extraction in ethyl acetate 3 times seemed not to be adequate. Therefore a similar protocol with water 
and ethyl acetate was tested, but with no repetition. $1.0 \mathrm{~g}$ of honey was added into $4 \mathrm{~mL}$ of deionized water and vortexed for $10 \mathrm{~min} .6 \mathrm{~mL}$ of ethyl acetate were added to the mixture and sonicated fro 10 min. The mixture was centrifuged at $4000 \mathrm{rpm}$ for $10 \mathrm{~min}$ and $3 \mathrm{~mL}$ of the upper phase was evaporated and mixed with $1 \mathrm{~mL}$ PBS (pH 7.5) by vortexing. Then $1 \mathrm{~mL}$ of hexane was added to the reconstituted extract. The mixture was vortexed for $2 \mathrm{~min}$ and centrifuged at $4000 \mathrm{rpm}$ for $10 \mathrm{~min}$. The lower phase was used for the assay. Again the threshold value T was lower than the cut-off Fm (data not shown). Therefore the assays were not valid. Regarding individual results, the discrimination between individual blank and spiked samples failed for lavender and lime tree honey (Table 7).

Table 7. Results of the analyses (measured current (nA)) of honey samples from different botanical origins after dilution of $1.0 \mathrm{~g}$ of honey with water and extraction in ethyl acetate $(4 \mathrm{~mL})$.

\begin{tabular}{|c|c|c|c|c|c|}
\hline \multicolumn{3}{|c|}{$\begin{array}{c}3 \mathrm{~mL} \text { water, } 6 \mathrm{~mL} \text { Ethyl Acetate, Dilution in } \\
\text { PBS (1/10) [28] }\end{array}$} & \multicolumn{3}{|c|}{$\begin{array}{c}4 \mathrm{~mL} \text { Water, } 6 \mathrm{~mL} \text { Ethyl Acetate, } 1 \mathrm{~mL} \text { PBS, } 1 \\
\text { mL Hexane }\end{array}$} \\
\hline $\begin{array}{c}\text { Botanical } \\
\text { origin }\end{array}$ & Blank & CAP $0.3 \mathrm{ng} / \mathrm{g}$ & $\begin{array}{c}\text { Botanical } \\
\text { origin }\end{array}$ & Blank & CAP $0.3 \mathrm{ng} / \mathrm{g}$ \\
\hline Lavender & 8326 & 6741 & Lavender & 5165 & 5295 \\
\hline Lime tree & 8038 & 7754 & Lime tree & 4939 & 5008 \\
\hline Acacia & 10662 & 10455 & Acacia & 6244 & 5692 \\
\hline Mountain & 10135 & 8223 & Mountain & 5416 & 5162 \\
\hline Forest & 8873 & 8441 & Scrubland & 5987 & 5145 \\
\hline Heather & 6297 & 5533 & Sunflower & 5283 & 4648 \\
\hline
\end{tabular}

PVPP and Ethyl Acetate Extraction

After testing many classical protocols for the honey extraction of CAP, none was satisfactory for the analyses of honey samples from different botanical origins. It was assumed that the high variability of the current measures came from antioxidant substances naturally occurring in honey (e.g., Polyphenols) that interfered with the detection of CAP. These substances were probably extracted in the same conditions as CAP and therefore perturbed the redox reaction that had to be measured. To remove this matrix effect, the use of poly(vinylpolypyrrolidoe) (PVPP) was tested. PVPP is a crosslinked homopolymer that binds with phenolic compounds by hydrogen bonding. PVPP can be used for the removal of phenolics and alkaloids from plant samples. PVPP is also used in wine to absorb some of the phenolic compounds and to eliminate some of the astringent tannins and molecules responsible for bitterness. The doses for using PVPP in wine vary from 10 to $30 \mathrm{~g} / \mathrm{hL}$ to 20 to $50 \mathrm{~g} / \mathrm{hL}$.

Two different concentrations of PVPP $(0.2 \mathrm{ng} / \mathrm{g}$ and $0.8 \mathrm{ng} / \mathrm{g}$ of honey) were tested by adding 1 $\mathrm{mL}$ and $4 \mathrm{~mL}$ of a solution of PVPP $20 \%$ in $1 \mathrm{~g}$ of honey. The samples and PVPP were kept in contact for 10 to $20 \mathrm{~min}$ at room temperature with continuous agitation. Then the mixture was centrifuged at 10,000 rpm for $5 \mathrm{~min}$. The supernatant was filtered onto Whatman paper. Then the filtered supernatant was extracted with $7 \mathrm{~mL}$ of ethyl acetate. The mixture was vortexed for $2 \mathrm{~min}$ and sonicated for $30 \mathrm{~min}$, then centrifuged at $5000 \mathrm{rpm}$ for $7 \mathrm{~min}$. The supernatant was collected in a glass tube and then was evaporated to dryness at $50{ }^{\circ} \mathrm{C}$ under nitrogen stream. The obtained extracts were reconstituted with $120 \mu \mathrm{L}$ of PBS-T.

With $0.2 \mathrm{ng} / \mathrm{g}$ of PVPP, the T value was equal to 1422 and the Fm value to 2374 . With $0.8 \mathrm{ng} / \mathrm{g}$ of PVPP, the T value was equal to 1582 and the Fm value to 1788. In both cases, $\mathrm{T}$ was lower than Fm, but the results seemed better when PVPP was added at the highest concentration $(0.8 \mathrm{ng} / \mathrm{g})$. When looking at the results for individual honey samples, all the blank samples were discriminated from the samples spiked with CAP to $0.3 \mathrm{ng} / \mathrm{g}$ (Table 8 ). The difference in percentage between the signal of blank and spiked samples was higher for sunflower and scrubland honey samples when PVPP was used at $0.8 \mathrm{ng} / \mathrm{g}$ and the results were similar for the other honey samples in both conditions. 
Table 8. Results of the analyses (measured current (nA)) of honey samples from different botanical origins addition of PVPP and extraction in ethyl acetate $(7 \mathrm{~mL})$.

\begin{tabular}{ccccc}
\hline & \multicolumn{2}{c}{ PVPP 0.2 ng/g } & \multicolumn{2}{c}{ PVPP 0.8 ng/g } \\
\hline Botanical origin & Blank & CAP 0.3 ng/g & Blank & CAP 0.3 ng/g \\
\hline Moutain & 1440 & 1090 & 1808 & 1347 \\
\hline Forest & 2502 & 1902 & 1995 & 1688 \\
\hline Scrubland & 2224 & 1937 & 1576 & 1043 \\
\hline Sunflower & 2244 & 1902 & 1977 & 1026 \\
\hline Spring & nd & 1929 & 2191 & 1511 \\
\hline Multifloral & 2764 & 2033 & 2018 & 1484 \\
\hline
\end{tabular}

\section{Preliminary Test with MWCNT-Modified SPCE}

After heating $2.0 \mathrm{~g}$ of acacia honey sample at $40{ }^{\circ} \mathrm{C}$ for $15 \mathrm{~min}$, honey samples were treated with $7 \mathrm{~mL}$ of ethyl acetate. The mixture was vortexed for $2 \mathrm{~min}$ and sonicated for $30 \mathrm{~min}$, then centrifuged at $5000 \mathrm{rpm}$ for $7 \mathrm{~min}$. The supernatant was collected in a glass tube and then was evaporated to dryness at $50{ }^{\circ} \mathrm{C}$ under nitrogen stream. The obtained extracts were reconstituted with $120 \mu \mathrm{L}$ of PBS$\mathrm{T}$. The threshold value T (1182) was lower than Fm (2719); therefore the assay was not valid. When looking at the results for individual honey samples, all the blank samples were discriminated from the samples spiked with CAP to $0.3 \mathrm{ng} / \mathrm{g}$, except mountain and forest honeys (Table 9). When we compared the difference in percentage between the signal of blank and spiked samples obtained previously with non-modified SPCE with the results obtained with these modified MWCNT-SPCE, the results were better with non-modified SPCE.

Table 9. Results of the analyses (measured current (nA)) of honey samples from different botanical origins after extraction of $2.0 \mathrm{~g}$ of honey in ethyl acetate $(7 \mathrm{~mL})$ and analyses with modified MWCNTSPCE.

\begin{tabular}{ccc}
\hline & Blank & CAP 0.3 ng/g \\
\hline Multifloral & 3444 & 1974 \\
\hline Multifloral & 1841 & 1810 \\
\hline Multifloral & 2627 & 1759 \\
\hline Lavender & 1561 & 1035 \\
\hline Mountain & 2220 & 2425 \\
\hline Forest & 2015 & 2358 \\
\hline
\end{tabular}

We finally tested the PVPP treatment and ethyl acetate extraction of honey samples from different botanical origins, followed by the analysis on MWCNT-SPCE. The results were not satisfactory $(T=1287>F m=2682)$. Even individual results for honey samples were less satisfactory than the previous test with PVPP and non-modified SPCE. Therefore it seemed that MWCNT electrodes were not interesting in our study to improve the detection capability of the assay. To check if matrix effects are responsible for this issue, some tests should be performed without matrices to compare the results with non-modified and MWCNT-SPCE.

\section{Discussion}

The preliminary results of this project were satisfactory because we were able to develop a screening test able to detect CAP at or below $0.3 \mathrm{ng} / \mathrm{g}$ in one honey sample. When individual honeys are analysed, the method was able to discriminate blank samples from samples spiked with CAP to $0.3 \mathrm{ng} / \mathrm{g}$. Therefore, this objective is fulfilled. However, as soon as the mean signals from honeys of different botanical origins were considered, it was no longer possible to discriminate blank samples and spiked samples because the variability in the signal due to each honey was too high. 
After an exhaustive bibliographical study, several extraction protocols for CAP in honey were selected and tested. A simple dilution of honey in buffer would have been an ideal sample preparation. However the results were not satisfactory when honeys from different botanical origins were tested. The extraction of CAP in ethyl acetate is actually a very usual procedure before analysis with ELISA kits or physico-chemical methods. We have tested different protocols with ethyl acetate and also some protocols with acetonitrile. It was not satisfactory. Matrix effect was not removed.

It was hypothesised that some components interfered with the electrochemical detection. Honey is a very complex matrix constituted of many molecules: sugars, proteins, vitamins, minerals, polyphenols, organic acids, lipids. The issue is that a number of these compounds are known to act as antioxidants (i.e., Polyphenols (flavonoids and non flavonoids), organic acids, vitamins (ascorbic acid), and enzymes (glucose oxidase and catalase)). Many of the honey flavonoids and phenolic acids are known to have antioxidant activity [29]. The amount and type of flavonoids vary depending on the flower source (i.e., Botanical origin). Honeys from seven different floral sources were analysed for in vitro antioxidant capacity and total phenolic content by Gheldhof et al. [30]. A correlation was observed between phenolic content, honey colour and antioxidant capacity of the investigated honeys. Honeys with dark colour have a higher total phenolic content and consequently a higher antioxidant capacity. Phenols are hydroxylated derivatives of benzene like hydroquinone. Polyhydroxy derivatives are called polyphenols. The polyphenols present in honey are mainly flavonoids (quercetin, luteolin, apigenin), phenol acids and their derivatives. The darker the honeys (like those from sunflower, buckwheat and honeydew), the richer they are in flavonoids. The structure of these flavonoids is very similar to those of hydroquinone (Figure 9). Furthermore the oxidation of polyphenols produces quinones. The oxidation of polyphenols could prevent the oxidation of hydroquinone and therefore all the electrochemical reaction that has to be measured.

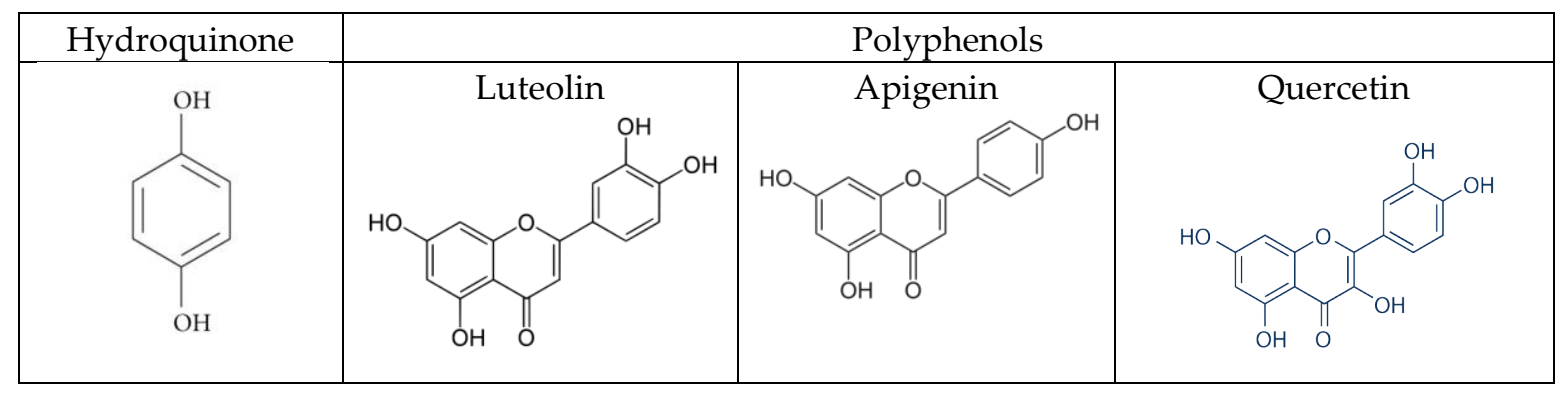

Figure 9. Similarities in the chemical structures of hydroquinone and three polyphenols.

The difficulty is to find a solvent which could extract these substances without extracting CAP. The issue is that phenolic acids and flavonols are usually extracted from honey in ethyl acetate or ethanol, like CAP. Only sugars are removed by this extraction. This co-extraction could explain the strong matrix effect we have observed. Some further researches (bibliographical studies) to find a solvent if possible that would extract CAP but not antioxidant components of honey. The solubility of flavonoids also depends on the $\mathrm{pH}$ [31]. Many natural flavonoids have extremely low solubility in aqueous media [32]. A combination of several solvents and the variation of $\mathrm{pH}$ for the extraction step should be tested.

One big challenge in the development of biosensors for the detection of analytes is working with biological matrices. This issue of interferences when handling biological samples has already been highlighted in several scientific publications. [33]. The sensitivity of the biosensor could be highly decreased because of matrix compounds interferences. We faced the same issue. While everything goes well in a buffer or in aqueous solution (e.g., Sensitivity, selectivity), the analysis of biological matrices is very complicated, especially when the matrix is as varied as honey. We assumed that some substances in the matrix (i.e., electroactive species) interfered with the electrochemical detection as it was already observed in previous works [34]. Very often research articles on CAP biosensors are evaluated only in buffer or aqueous solution [35]. When the method is applied to biological matrices, only one or a few matrix samples are analysed [36-38]. It is only a proof of concept for the developed 
biosensor but it is not a full evaluation of the actual performance of the method and of its applicability in routine. A full validation requires the analyses of at least twenty samples from different origins (i.e., Honeys from different botanical and geographical origins) for the determination of specificity and detection capabilities $[2,26]$.

The objective of a screening method is to be able to detect CAP in any type of honey. In routine analyses, we daily carry out negative quality controls (QC) (blank samples) and positive QCs (samples spiked with CAP at the detection capability (or limit of detection)). The analysis of these QC makes it possible to determine the daily $\mathrm{T}$ and Fm. Thus we can conclude if the test of the day is indeed valid. Finally, the cut-off Fm is used to conclude on the positivity of the unknown samples analysed on the same day. Therefore at least two blank honey samples and two spiked honey samples from different botanical origins preferably have to be analysed. However, if the signals are too different between botanical origins, this management of routine analyses will not be possible. Therefore we must develop an analytical method, combining sample extraction and analysis on the biosensor, able of analysing all types of honey simultaneously. Otherwise, 2 negative and 2 positive QCs would be necessary for each floral origin to be analysed on the day of the test, which would be completely impractical.

If a common extraction protocol removing matrix effects is not available, we could consider in the future making groups within the variety of honeys. To form these groups, we would need more results to be able to find which types of honey could be integrated in each group. We assumed that the groups could be linked to the colour of honey, to its $\mathrm{pH}$ for instance. This will require analysing QCs from each group for analysis of unknown samples, based on the botanical origin of the samples to be analysed.

As a conclusion, SPCE are attractive for the development of biosensors for the detection of antimicrobial residues in foodstuffs because they are relatively affordable, disposable (no cleaning process, no memory effect), and can be portable (i.e., small, robust, simple, portable instrumentation) [33]. Magnetic beads are usually useful because they help minimising the matrix effect (i.e., blocking of the binding sites on the electrode) due to the washing steps, but they also enable quicker analysis because they are in suspension. In addition, the sensitivity is improved and separate the immunoreaction step from the electrochemical detection step. Unfortunately regarding the complexity of honey matrix and the great variety of its components, even the use of magnetic beads did not allow to remove all matrix effects. For more than ten years, nanomaterials (NMs) and their outstanding characteristics are widely used in the development of very sensitive electrochemical biosensors [39,40]. Nanomaterials improves the sensitivity of biosensors by increasing the surface area of the transduction zone. They can improve the electrical conductivity in the case of electrochemical biosensors and reduce the background noise associated with the samples analyzed (matrix effect). Unfortunately it seemed that the tested modified SPCE did not give better results than non-modified SPCE, and even gave worst results. Further tests in buffer should be conducted to verify if the problem was due to the strong matrix effect of the honey.

There are many perspectives to this work:

- The work will continue to develop more efficient extraction protocols, able to remove or at least lower the strong matrix effect of honey.

- The positive effect of PVPP on the reduction of the matrix effect will continue to be investigated, probably firstly by increasing its concentration.

- We will compare different electrochemical modes of detection: amperometry, voltammetry (i.e., voltamperometry).

- The use of nanomaterials could be explored to improve performance characteristics of the electrode (i.e., Modified SPCE).

- An aptamer will be evaluated in replacement of the antibody to detect CAP. Aptamers are already easily found commercially because the sequence is known [41]; many articles are dealing with aptasensors for CAP $[39,42]$. 
- After chloramphenicol, we will develop biosensors for other banned antimicrobials (i.e., Nitrofuran metabolites) and finally develop a multiplex method for the simultaneous detection of at least all these banned substances.

Funding: This research received no external funding.

Conflicts of Interest: The authors declare no conflict of interest.

\section{References}

1. European Commission. Commission Regulation (EC) $N^{\circ} 470 / 2009$ laying down Community procedures for the establishment of residue limits of pharmacologically active substances in foodstuffs of animal origin. Eur. Parliement Counc. 2009, L152, 11-22.

2. European Commission. Commission Decision (EC) $N^{\circ}$ 2002/657 of 12 August 2002 implementing Council Directive 96/23/EC concerning the performance of analytical methods and interpretation of results. Off. J. Eur. Communities 2002, L221, 8-36.

3. European Commission. Council directive 96/23/EC of 29 April 1996 on measures to monitor certain substances and residues thereof in live animals and animal products and repealing Directives 85/358/EEC and 86/469/EEC and Decisions 89/187/EEC and 91/664/EEC. 1996, L125, 10-32.

4. European Commission. Regulation (EU) 2017/625 of the European Parliament and of the Council of 15 March 2017 on official controls and other official activities performed to ensure the application of food and feed law, rules on animal health and welfare, plant health and plant protection products. Off. J. Eur. Union 2017, 95, 1-142.

5. Shukla, P.; Bansode, F.; Singh, R. Chloramphenicol Toxicity: A Review. J. Med. Med. Sci. 2011, 2, 1313-1316.

6. EEC. Commission Regulation (EC) No 1430/94 of 22 June 1994 amending Annexes I, II, III and IV of Council Regulation (EEC) No 2377/90 laying down a Community procedure for the establishment of maximum residue limits of veterinary medicinal products in foodstuffs of animal origin. Off. J. Eur. Communities 1994, $156,6-8$.

7. Gaudin, V.; Cadieu, N.; Maris, P. Inter-laboratory studies for the evaluation of ELISA kits for the detection of chloramphenicol residues in milk and muscle. Food Agric. Immunol. 2003, 15, 143-157.

8. Biernacki, B. ELISA validation and determination of cut-off level for chloramphenicol residues in honey. Bull. Vet. Inst. Pulawy 2015, 59, 353-356, doi:10.1515/bvip-2015-0052.

9. Tao, X.; Jiang, H.; Zhu, J.; Wang, X.; Wang, Z.; Niu, L.; Wu, X.; Shi, W.; Shen, J. An ultrasensitive chemiluminescent ELISA for determination of chloramphenicol in milk, milk powder, honey, eggs and chicken muscle. Food Agric. Immunol. 2014, 25, 137-148, doi:10.1080/09540105.2012.753513.

10. Schortini, G.; Annunziata, L.; Haouet, M.N.; Benedetti, F.; Krusteva, I.; Galarini, R. ELISA qualitative screening of chloramphenicol in muscle, eggs, honey and milk: method validation according to the Commission Decision 2002/657/EC criteria. Anal. Chim. Acta 2005, 535, $43-48$.

11. Diblikova, I.; Cooper, K.M.; Kennedy, D.G.; Franek, M. Monoclonal antibody-based ELISA for the quantification of nitrofuran metabolite 3-amino-2-oxazolidone in tissues using a simplified sample preparation. Anal. Chim. Acta 2005, 540, 285-292.

12. Chen, D.; Delmas, J.-M.; Hurtaud-Pessel, D.; Verdon, E. Development of a multi-class method to determine nitroimidazoles, nitrofurans, pharmacologically active dyes and chloramphenicol in aquaculture products by liquid chromatography-tandem mass spectrometry. Food Chem. 2020, 311, 125924, doi:https://doi.org/10.1016/j.foodchem.2019.125924.

13. Shendy, A.H.; Al-Ghobashy, M.A.; Gad Alla, S.A.; Lotfy, H.M. Development and validation of a modified QuEChERS protocol coupled to LC-MS/MS for simultaneous determination of multi-class antibiotic residues in honey. Food Chem. 2016, 190, 982-989, doi:10.1016/j.foodchem.2015.06.048.

14. Robert, C.; Gillard, N.; Brasseur, P.Y.; Pierret, G.; Ralet, N.; Dubois, M.; Delahaut, P. Rapid multi-residue and multi-class qualitative screening for veterinary drugs in foods of animal origin by UHPLC-MS/MS. Food Addit. Contam. Part A 2012, 30, 443-457, doi:10.1080/19440049.2012.751632.

15. Gaudin, V.; Maris, P. Development of a biosensor based immunoassay for screening of chloramphenicol residues in milk. Food Agric. Immunol. 2001, 13, 77-86.

16. Ferguson, J.; Baxter, A.; Young, P.; Kennedy, G.; Elliott, C.; Weigel, S.; Gatermann, R.; Ashwin, H.; Stead, S.; Sharman, M. Detection of chloramphenicol and chloramphenicol glucuronide residues in poultry 
muscle, honey, prawn and milk using a surface plasmon resonance biosensor and Qflex kit chloramphenicol. Anal. Chim. Acta 2005, 529, 109-113.

17. Pohanka, M.; Skládal, P. Electrochemical biosensors-Principles and applications. J. Appl. Biomed. 2008, 6, $57-64$.

18. Mishra, G.K.; Barfidokht, A.; Tehrani, F.; Mishra, R.K. Food Safety Analysis Using Electrochemical Biosensors. Foods (Basel, Switzerland) 2018, 7, 141, doi:10.3390/foods7090141.

19. Felix, F.S.; Angnes, L. Electrochemical immunosensors - A powerful tool for analytical applications. Biosens. Bioelectron. 2018, 102, 470-478, doi:10.1016/j.bios.2017.11.029.

20. Khoshbin, Z.; Verdian, A.; Housaindokht, M.R.; Izadyar, M.; Rouhbakhsh, Z. Aptasensors as the Future of Antibiotics Test Kits-A Case Study of the Aptamer Application in the Chloramphenicol Detection. Biosens. Bioelectron. 2018, doi:10.1016/j.bios.2018.09.060.

21. Thévenot, D.R.; Toth, K.; Durst, R.A.; Wilson, G.S. Electrochemical biosensors: recommended definitions and classification. Biosens. Bioelectron. 2001, 16, 121-131, doi:10.1016/s0956-5663(01)00115-4.

22. Conzuelo, F.; Gamella, M.; Campuzano, S.; Pinacho, D.G.; Reviejo, A.J.; Marco, M.P.; Pingarrón, J.M. Disposable and integrated amperometric immunosensor for direct determination of sulfonamide antibiotics in milk. Biosens. Bioelectron. 2012, 36, 81-88, doi:10.1016/j.bios.2012.03.044.

23. Conzuelo, F.; Gamella, M.; Campuzano, S.; Reviejo, A.J.; Pingarrón, J.M. Disposable amperometric magneto-immunosensor for direct detection of tetracyclines antibiotics residues in milk. Anal. Chim. Acta 2012, 737, 29-36, doi:10.1016/j.aca.2012.05.051.

24. Gamella, M.; Campuzano, S.; Conzuelo, F.; Esteban-Torres, M.; de las Rivas, B.; Reviejo, A.J.; Munoz, R.; Pingarron, J.M. An amperometric affinity penicillin-binding protein magnetosensor for the detection of [small beta]-lactam antibiotics in milk. Analyst 2013, 138, 2013-2022, doi:10.1039/c3an36727d.

25. Conzuelo, F.; Ruiz-Valdepeñas Montiel, V.; Campuzano, S.; Gamella, M.; Torrente-Rodríguez, R.M.; Reviejo, A.J.; Pingarrón, J.M. Rapid screening of multiple antibiotic residues in milk using disposable amperometric magnetosensors. Anal. Chim. Acta 2014, 820, 32-38, doi:10.1016/j.aca.2014.03.005.

26. CRL. Guideline for the Validation of Screening Methods for Residues of Veterinary Medicines (Initial Validation and Transfer). 2010. pp. 1-18. Available online: http://ec.europa.eu/food/food/chemicalsafety/residues/lab_analysis_en.htm Guideline_Validation_Screening_en.pdf (accessed on).

27. Yan, L.; Luo, C.; Cheng, W.; Mao, W.; Zhang, D.; Ding, S. A simple and sensitive electrochemical aptasensor for determination of Chloramphenicol in honey based on target-induced strand release. J. Electroanal. Chem. 2012, 687, 89-94, doi:10.1016/j.jelechem.2012.10.016.

28. Xiao, L.; Xu, R.; Yuan, Q.; Wang, F. Highly sensitive electrochemical sensor for chloramphenicol based on MOF derived exfoliated porous carbon. Talanta 2017, 167, 39-43, doi:10.1016/j.talanta.2017.01.078.

29. Pyrzynska, K.; Biesaga, M. Analysis of phenolic acids and flavonoids in honey. TrAC Trends Anal. Chem. 2009, 28, 893-902, doi:10.1016/j.trac.2009.03.015.

30. Gheldof, N.; Engeseth, N.J. Antioxidant Capacity of Honeys from Various Floral Sources Based on the Determination of Oxygen Radical Absorbance Capacity and Inhibition of in Vitro Lipoprotein Oxidation in Human Serum Samples. J. Agric. Food Chem. 2002, 50, 3050-3055, doi:10.1021/jf0114637.

31. Chebil, L.; Humeau, C.; Anthoni, J.; Dehez, F.; Engasser, J.-M.; Ghoul, M. Solubility of Flavonoids in Organic Solvents. J. Chem. Eng. Data 2007, 52, doi:10.1021/je7001094.

32. Romera-Torres, A.; Romero-González, R.; Martínez Vidal, J.L.; Garrido Frenich, A. Comprehensive tropane alkaloids analysis and retrospective screening of contaminants in honey samples using liquid chromatography-high resolution mass spectrometry (Orbitrap). Food Res. Int. 2020, 133, 109130, doi:10.1016/j.foodres.2020.109130.

33. Yamanaka, K.; Vestergaard, M.d.C.; Tamiya, E. Printable Electrochemical Biosensors: A Focus on ScreenPrinted Electrodes and Their Application. Sensors (Basel, Switzerland) 2016, 16, 1761, doi:10.3390/s16101761.

34. Taleat, Z.; Khoshroo, A.; Mazloum-Ardakani, M. Screen-printed electrodes for biosensing: a review (20082013). Microchim. Acta 2014, 181, 865-891, doi:10.1007/s00604-014-1181-1.

35. Shaheen, A.; Taj, A.; Liberzeit, P.; Mujahid, A.; Hameed, S.; Yu, H.; Mehmood, A.; Webster, T.; Rasheed, M.; Khan, W.; et al. Design of heterostructured hybrids comprising ultrathin 2D bismuth tungstate nanosheets reinforced by chloramphenicol imprinted polymers used as biomimetic interfaces for masssensitive detection. Colloids Surf. B Biointerfaces 2020, 188, 110775, doi:10.1016/j.colsurfb.2020.110775. 
36. Wu, Y.-Y.; Huang, P.; Wu, F.-Y. A label-free colorimetric aptasensor based on controllable aggregation of AuNPs for the detection of multiplex antibiotics. Food Chem. 2020, 304, 125377, doi:10.1016/j.foodchem.2019.125377.

37. Gaudin, V. The Growing Interest in Development of Innovative Optical Aptasensors for the Detection of Antimicrobial Residues in Food Products. Biosensors 2020, 10, 21.

38. Gaudin, V. Receptor-based electrochemical biosensors for the detection of contaminants in food products. In Electrochemical Biosensors; Elsevier: Amsterdam, The Netherlands, 2019; pp. 307-365. doi:10.1016/b978-012-816491-4.00011-5.

39. Dong, X.; Yan, X.; Li, M.; Liu, H.; Li, J.; Wang, L.; Wang, K.; Lu, X.; Wang, S.; He, B. Ultrasensitive detection of chloramphenicol using electrochemical aptamer sensor: A mini review. Electrochem. Commun. 2020, 106835, doi:10.1016/j.elecom.2020.106835.

40. Lu, L.; Hu, X.; Zhu, Z.; Li, D.; Tian, S.; Chen, Z. Review-Electrochemical Sensors and Biosensors Modified with Binary Nanocomposite for Food Safety. J. Electrochem. Soc. 2020, 167, 037512, doi:10.1149/2.0122003jes.

41. Lorenz, C.S.R. Aptamers to Antibiotics. In The Aptamer Handbook; Klussmann, D.S., Ed.; Wiley-VCH Verlag GmbH \& Co. KGaA: Weinheim, Germany, 2006; pp. 116-130. doi:10.1002/3527608192.ch5.

42. Mehlhorn, A.; Rahimi, P.; Joseph, Y. Aptamer-Based Biosensors for Antibiotic Detection: A Review. Biosensors (Basel) 2018, 8, doi:10.3390/bios8020054.

Publisher's Note: MDPI stays neutral with regard to jurisdictional claims in published maps and institutional affiliations.

(C) 2020 by the authors. Submitted for possible open access publication under the terms and conditions of the Creative Commons Attribution (CC BY) license (http://creativecommons.org/licenses/by/4.0/). 